\title{
Mapping of female breast cancer incidence and mortality rates to socioeconomic factors cohort: Path diagram analysis
}

Qiongle Peng ( $\sim$ pengxiaoman@ujs.edu.cn )

Affiliated Hospital of Jiangsu University https://orcid.org/0000-0001-9035-3093

\section{Xiaoling Ren}

Wuxi Traditional Chinese Medicine Hospital

Bing Cui

Affiliated Hospital of Jiangsu University

Henggui Cui

Affiliated Hospital of Jiangsu University

\section{Research article}

Keywords: Regression analysis, path diagram analysis, breast cancer, incidence, mortality, socioeconomic factors

Posted Date: December 30th, 2020

DOl: https://doi.org/10.21203/rs.3.rs-67659/v2

License: (9) This work is licensed under a Creative Commons Attribution 4.0 International License. Read Full License

Version of Record: A version of this preprint was published at Frontiers in Public Health on February 1st, 2022. See the published version at https://doi.org/10.3389/fpubh.2021.761023. 
Mapping of female breast cancer incidence and mortality rates to socioeconomic factors cohort: Path diagram analysis

$$
\text { Qiongle Peng }^{1^{*}} \text {, Xiaoling Ren }{ }^{2} \text {, Bing Cui }{ }^{1} \text {, Henggui Cui }{ }^{1}
$$

1. Department of Blood Transfusion, Affiliated Hospital of Jiangsu University, Zhenjiang 212013, P. R. China

2. Central Laboratory, Wuxi Traditional Chinese Medicine Hospital, Wuxi 214071, P.

R. China

*Corresponding author: pengxiaoman@ujs.edu.cn (Qiongle Peng) 


\section{Abstract}

BACKGROUND: Breast cancer is the leading cause of death in females around the world. Its occurrence and development has been linked to genetic factors, living habits and health conditions, and socioeconomic factors. Comparisons of incidence and mortality rates of female breast cancer are useful approaches to define cancer-related socioeconomic disparities. METHODS: This was a retrospective observational cohort study on breast cancer of females in several developed countries between 1980 and 2012. The path diagram analysis for five factors, i.e. years, population, gross domestic product, gross domestic product per capita, and unemployment rate, were conducted using Excel database function, and the effects on breast cancer incidence and mortality rates were analyzed. International Agency for Research on Cancer's CANCERMondial clearinghouse was used to determine the incidence and mortality rates of female breast cancer data from several developed countries for 1980-2012. RESULTS: The relationship between socioeconomic factors and the occurrence and development of breast cancer did not follow a monotonic function. We found a positive, significant association of national public wealth on the incidence and mortality of breast cancer. The path coefficients in the structural equations model are -0.51 and -0.39 , respectively. In addition to the significant relationship between individual physical and psychological characteristics, social pressure, such as unemployment rate has a significant impact on the incidence and mortality of breast cancer. The path coefficients in the structural equations model are all 0.2. The path coefficients of individual economic wealth to the incidence rate and mortality rate of breast cancer is 0.18 and 
0.27, respectively. CONCLUSIONS: A significant statistical relationship between the socioeconomic development and the crude rates of female breast cancer was shown in this study. The incidence and mortality rates of breast cancer can be regulated effectively by a moderate increase in national public wealth, and clearly was affected by the individual's economic wealth. In addition, the influence of social pressure (e.g., unemployment rate) on the incidence and mortality of breast cancer was not typical monotonous. The survival rate of breast cancer determined by the ratio of mortality rate to incidence rate also showed a similar pattern with socioeconomic factors.

Key words: Regression analysis, path diagram analysis, breast cancer, incidence, mortality, socioeconomic factors

\section{Background}

Through history, health was always one of the most fundamental issues of human development. In most of the historical stages, the culture, economy, trade and war experienced in each country were part of objective existence, and closely associated with individual health problems [1]. Health problems faced by human beings were influenced by the following aspects [2]. First, the time [3] and space [4] on which human beings depend for survival constitutes the objective basis for the development of human society [5]. The second reason was the basic living necessities. Thirdly, human health issues are strongly tied to special spatial conditions $[6,7]$, such as longitude, latitude, altitude, temperature [8]. These environmental factors will cause or induce people to form a life and behavior habit or culture [9] that matches the geographical environmental conditions $[10,11]$. Fourthly, human health problems 
tightly relate to social development [12-14]. At different stages of development, human beings face different threats of diseases $[3,15]$.- The types and severity of diseases were different in different regions and ethnic groups at the same historical stage [16]. Hunger [17], disease [18] and death are the three basic threats for the objective existence of species [19], and the same is true of the advanced animals, i.e. human beings [20] (as shown in Fig. 1).

Todays, cancers have brought a huge threat to human health. Human beings have made considerable progress in dealing with breast cancer, such as disease prevention [21], cancer screening [22], etiological analysis [23], targeted drugs [24, 25] and clinical surgery [26]. Despite important advances in the understanding of oncogenesis and development in the past decades, breast cancer remains one of the most common cancers diagnosed among women and the leading cause of female cancer death [27]. The risk of breast cancer was significantly increased in developing counties [28]. The occurrence and development of breast cancer is complex and multi-stage processes, which prompt humankind to tackle at least two short or long-term goals. On the one hand, it is urgent to develop new-targeted drugs or explore minimally invasive surgical techniques. On the other hand, it is important to consider the factors of breast cancer occurrence and development from the perspective of social/environment factors [29, 30] and their interactions [31] (e.g. support [32] and education, networks [33], emotion [34]) on breast cancer occurrence and development. Numbers of individual and environmental factors may contribute to the risk of breast cancer and the prognosis in patients. Recently, the correlations between socioeconomic status and breast cancer 
incidence and mortality rates are increasingly recognized.

Studies have demonstrated that nature environmental, host genetic, and socioeconomic factors influence the breast cancer prevalence landscape with a farreaching influence on racial disparity to subtypes of breast cancer [35]. The socioeconomic effects on the incidence and death of the breast cancer need pay enough attentions, the socio-economic disparities in breast cancer survival prevail even in this relatively homogenous society [36]. Note that the function of public wealth and individual wealth are different during the intervene process. Thus, the lower screening attendance for women with lower socioeconomic status, and higher socioeconomic status is linked to higher incidence but lower case fatality [37]. Importantly, there is limited understanding of the contribution of social factors to control patterns [30]. Further, the influence and interaction of many socioeconomic factors (e.g. disposable wealth and pressures of life) on breast cancer of women is complex, and it is difficult to expose the dominate factors by cutting off the cross effects of affect factors. As shown in Figure 2, the influence factors both from nature and society are various and are not available in a statistics way. In order to investigate the influence maps between the socioeconomic issues and breast cancer, we focused on two groups socioeconomic data, one is endogenous wealth and distribution related to economic development (General Domestic Products, GDP; General Domestic Products Per Capita, GDPPC), and the other is exogenous completion and pressure related to individual survive (unemployment rate; population). These socioeconomic factors were readily available and involved in cancer control, such as population-level incidence rates, death rates and 
survival rates. Further, socioeconomic factors based on development were investigated by using stepwise regression analysis and path diagram analysis-. This study is critical for the influences of the socioeconomic factors on the development of breast cancer, with a purpose of providing socioeconomic information for the high risk screening and diagnosis, prevention and managing long-term surveillance care of female breast cancer. This study is also useful for the instructive intervention of social welfare and public health policy, with consideration of the prevention and treatment on breast cancer of women in developed countries and regions.

\section{Methods}

In this study, a retrospective observational cohort study on breast cancer of females in Denmark, Norway, Italy, New Zealand, Israel, France, Germany and Japan between 1980 and 2012 was carried out. The regression analysis and multivariate analysis (path diagram analysis) for five factors, i.e. years, population, gross domestic product, gross domestic product per capita, and unemployment rate, were adopted using Excel database function, and the effects of socioeconomic factors on breast cancer incidence and mortality rates were analyzed. The breast cancer incidence and mortality data from 1980 to 2012 were obtained from Global Cancer Observatory (GCO) (http://gco.iarc.fr/\#cancer-overtime). The socioeconomic data (including GDP, GDPPC, unemployment rate, and population) of several representative developed countries were obtained from National Accounts Main Aggregates Database (https://unstats.un.org/unsd/snaama/Basic). An illustration of the incidence and 
mortality of breast cancer is provided in Figure 3.

Path diagram analysis is a form of structural equation model (SEM) and is generally tested by regression analysis [38]. The structural model is fitted by mathematical statistics methods and principles [39]. After the series test and analysis, the most suitable model was available to represent multiple complex relationships between independent variables and variables. In this study, we focused on certain socioeconomic factors such as time-dependent public wealth, living environment, including social population and unemployment ratio [40] (reads social pressure), and individual economic wealth. As well known, these factors have complex interactions with each other. Therefore, path diagram analysis, based on multiple linear regression models, was used to explore the factors which influence female breast cancer using multi-dimensional causality and related strength analysis. The multivariate multiple linear regression formula was expressed as follows:

$$
\mu_{Y}=\beta_{0}+\beta_{1} X_{1}+\cdots \beta_{5} X_{5}
$$

where $\beta_{0}$ is intercept, $\beta_{1}, \beta_{2} \ldots \beta_{5}$ is partial regression coefficient. By fitting the regression equation of samples $\hat{Y}=\mathrm{a}+b_{1} X_{1}+\cdots b_{5} X_{5}$, and the least square method was used to find coefficients to minimize the sum of squares (SS) of residual errors.

$$
S S=\sum_{i=1}^{5}\left(Y_{i}-a-b_{1} X_{i 1}-b_{2} X_{i 2} \ldots-b_{5} X_{i 5}\right)^{2}
$$

The structure of path diagram analysis was represented by a series of regression parameters, as seen in Table 1. Hypotheses involved the correlational and regressionlike relations between the incidence/mortality rate and the socioeconomic factors. That is, some factors were observed variables and the others were latent variables. There 
might be a relationship between the observed variables and latent variables, and some variables maybe functions of other variables. In this study, we used incidence and mortality rates as dependent variable. Generally, temporal and spatial variables were regarded as the most basic independent variable, and the other factors were function of time.

Table 1 Regression sketch of numerical variable for the path diagram analysis

\begin{tabular}{cccccccl}
\hline Route & \multicolumn{6}{c}{ Regression parameters } & \multicolumn{1}{c}{ Function } \\
\hline $\mathrm{R}_{1}$ & $X_{1}$ & $X_{2}$ & $X_{3}$ & $X_{4}$ & $X_{5}$ & $Y_{1}$ & $Y_{1}=f_{1}\left(X_{1}, X_{2}, \ldots X_{5}\right)$ \\
$\mathrm{R}_{2}$ & $X_{1}$ & $X_{2}$ & $X_{3}$ & $X_{4}$ & $Y_{2}$ & \\
$\mathrm{R}_{3}$ & $X_{1}$ & $X_{2}$ & $X_{3}$ & $Y_{3}$ & & $Y_{3}=f_{2}\left(X_{1}, X_{2}, \ldots X_{4}\right)$ \\
$\mathrm{R}_{4}$ & $X_{1}$ & $\left.X_{2}, X_{2}, X_{3}\right)$ \\
$\mathrm{R}_{5}$ & $X_{1}$ & $Y_{5}$ & & & $Y_{4}=f_{4}\left(X_{1}, X_{2}\right)$ \\
\hline
\end{tabular}

Note: The sample includes information for numerical variables from several representative countries (e.g. Denmark, Norway, New Zealand, Canada, Israel, France, Germany, Japan), including information on economics and breast cancer during 1980-2012. $\mathrm{R}_{i}(i=1-5)$ is the stepwise route of the regression analysis. During each process of regression, $X_{\mathrm{i}}$ is an independent variable, which consists of years, population, gross domestic product (GDP), gross domestic product per capita (GDPPC), and unemployment rate (UR). $Y_{\mathrm{j}}(j=1-5)$ is the dependent variable, in this case, the incidence rate and mortality rate of breast cancer. During the process of stepwise regression analysis, note that the identity of $X_{\mathrm{i}}$ (except for the lowest-order independent variable $X_{1}$ ) would transform into a dependent variable $Y_{\mathrm{j}}$.

A graphical explanation of the process of path diagram analysis and the raw fivefactor model was shown in Figure. 4z. Clearly, in this study, we assumed that the five factors $\left(x_{1}, x_{2}, x_{3}, x_{4}, x_{5}\right)$ of years, population, GDP, GDPPC, and unemployment rate affect breast cancer incidence and mortality rates $\left(y_{1}, y_{2}\right)$. Further, we supposed that time was the most basic variable, and GPD was a low-order variable. GDP as a function of social wealth was impacted by years, a measure of time, GDPPC, population, and unemployment rate, which were all high-order variables and affected by other variables. The survival rate of breast cancer was measured using the mortality-to-incidence ratio (MIR) [41] and to illustrate the effects of socioeconomic factors [42]. All variables were 
normalized before regression analysis. In mathematical form, the regression equation of path diagram analysis was formed by linking these variables with some coefficients.

\section{Results}

Path analysis is one form of structural equations model (SEM), which initial was applied in econometrics. The attractive feature is that uses the structural equations to present the implied values and compare them with the observed values [46]. That is, it explicitly assumes that every variable we observe is an imperfect measure of some potential causal variables and that the causality of interests is always between these potential variables. During the modeling of structural equations, there are three matrices (A, S, and F) which are defined by McArdle and McDonald [47]. The so-called structural equations consist of these matrices, as expressed byC $=\mathrm{F}(\mathrm{I}-\mathrm{A})^{-1} \mathrm{~S}(\mathrm{I}-$ A) ${ }^{-1 \prime} F^{\prime}$. Where matrix $\mathbf{A}$ contains paths for asymmetric relations, $\mathbf{S}$ contains correlations and residual variances for symmetric relations, and matrix $\mathbf{F}$ filter the observed variables from the total data. Therefore, path diagram analysis is interesting and allow for novel applications [46, 48, 49]. In this study, it is possible to form three path analysis models, according to the previous assumptions about high-order variables (i.e. implied values) and low-order variables (i.e. observed values). The correlation coefficients and determination coefficients of the regression analysis of these three models are shown in Table 2. It can be seen that there is a significant relationship between breast cancer incidence and time and socioeconomic factors (i.e. population, GDP, GDPPC, and UR) ( $>0.8)$, except for factors identified by the stepwise regression 
model. The fifth regression analysis (for the model of population versus time, $R<0.2$ ), there are significant multi-factor correlations. This finding verifies that the model as a whole is reasonable.

Table 2 Model summary for the multivariable regression analysis

\begin{tabular}{llccccc}
\hline Model & Regression statistics & Step I & Step II & Step III & Step IV & Step V \\
\hline Model 1 & Multiple R & 0.8389 & 0.7698 & 0.5657 & 0.7858 & 0.1408 \\
& R Square & 0.7038 & 0.5927 & 0.3199 & 0.6176 & 0.0198 \\
& Adjusted R Square & 0.6986 & 0.5869 & 0.3128 & 0.6149 & 0.0164 \\
& Std. Error & 0.0968 & 0.2041 & 0.1624 & 0.1043 & 0.2116 \\
Model 2 & Multiple R & 0.6171 & 0.7434 & 0.7859 & 0.7858 & 0.1408 \\
& R Square & 0.3808 & 0.5527 & 0.6176 & 0.6176 & 0.0198 \\
& Adjusted R Square & 0.3720 & 0.5480 & 0.6149 & 0.6149 & 0.0164 \\
& Std. Error & 0.1552 & 0.2135 & 0.1043 & 0.1043 & 0.2116 \\
Model 3 & Multiple R & 0.8340 & 0.4751 & 0.7420 & 0.7858 & 0.1408 \\
& R Square & 0.6956 & 0.2257 & 0.5506 & 0.6176 & 0.0198 \\
& Adjusted R Square & 0.6913 & 0.2175 & 0.5474 & 0.6149 & 0.0164 \\
& Std. Error & 0.0934 & 0.1733 & 0.2137 & 0.1043 & 0.2116 \\
\hline
\end{tabular}

Note: Complex correlation coefficient $R$ is used to measure the degree of correlation between independent variables $x$ and $y$. Complex determination coefficient $R^{2}\left(\mathrm{R}^{2}=1-S S\right.$ (residual)/ $S S($ all $)$ ) is used to explain the degree of variation of dependent variable $y$ with the independent variable $x$, i.e. determine the fitting effect of dependent variable $y$. The adjusted complex coefficient $R^{2}\left(R_{a d j}^{2}=1-\frac{M S(\text { residual })}{M S(\text { all })}\right)$ can reflect the percentage of independent variable influencing dependent variable. Std. Error is used to measure the degree of fitting. The sample size is 288 in this study.

The main function of Analysis of Variance (ANOVA) table is used to judge the regression effect of regression model by joint hypotheses test ( $F$ test). The ANOVA data of each step regression analysis is listed in Table 3. In the process of decreasing regression, the degree of freedom $(d f)$ of potential variables is reduced by one for each regression. The significant level, or F statistics for each step of the regression analysis has different $\mathrm{P}$ values, which is less than the stated significance level of 0.05 . Therefore, the regression equation for each step has the statistical significance of regression process. Further, the obtained interception and partial regression coefficient are used to 
express the each regression equation. The revalued coefficients for the selected models of the multivariable analyses are presented in Table 4.

Table 3 Analysis of variance (ANOVA) results of regression models for incidence rate

\begin{tabular}{|c|c|c|c|c|c|c|}
\hline Step & Variation sources & $d f$ & $S S$ & $M S$ & $F$ & Significance $\mathrm{F}$ \\
\hline \multirow[t]{3}{*}{ I } & Regression & 5 & 4.0823 & 0.8164 & 47.8654 & $9.48 \mathrm{E}-36$ \\
\hline & Residual & 282 & 4.8101 & 0.0171 & & \\
\hline & Total & 287 & 8.8924 & & & \\
\hline \multirow[t]{3}{*}{ II } & Regression & 4 & 17.1575 & 4.2894 & 102.9645 & $5.35 \mathrm{E}-54$ \\
\hline & Residual & 283 & 11.7895 & 0.0417 & & \\
\hline & Total & 287 & 28.9470 & & & \\
\hline \multirow[t]{3}{*}{ III } & Regression & 3 & 3.5235 & 1.1745 & 44.5455 & $1.27 \mathrm{E}-23$ \\
\hline & Residual & 284 & 7.4880 & 0.0264 & & \\
\hline & Total & 287 & 11.0115 & & & \\
\hline \multirow[t]{3}{*}{ IV } & Regression & 2 & 5.0085 & 2.5043 & 230.1414 & $3.23 \mathrm{E}-60$ \\
\hline & Residual & 285 & 3.1012 & 0.0109 & & \\
\hline & Total & 287 & 8.1097 & & & \\
\hline \multirow[t]{3}{*}{$\mathrm{V}$} & Regression & 1 & 0.2594 & 0.2594 & 5.7892 & 0.0167 \\
\hline & Residual & 286 & 12.8143 & 0.0448 & & \\
\hline & Total & 287 & 13.0737 & & & \\
\hline
\end{tabular}

Note: Significance F (F significant statistic) has the P values that is less than the significance level of 0.05 , so the regression equation has a statistical significance.

Note that the P-value of items of "intercept", "year" and "population" in the first regression are larger than the significance level of 0.05 . The item of "GDPPC" in the second regression also has no statistical significance $\left({ }^{* *} \mathrm{P}>0.05\right)$. These shows that, the hypothesis that female breast cancer mortality is a function of time and population is not statistically significant in the structural equations model. In addition, the hypothesis that population is a function of GDPPC has no statistically significance. Therefore, some path coefficients in this structural equations models need eliminated for the reasonable hypothesis and correction SEM model. According to the path coefficients we can understand and identify the cause-effect relationship between the latent variables. Further, the path diagram based on the structural equations models are 
obtained and as shown in Figure. 5. In the path diagram model, the magnitude of the path coefficient indicates the relationship between the influence degree of variables and dependent variables, while the positive and negative values indicate the positive and negative effects of the influence trend.

In Figure. 5(a), year was the most basic time variable which was always related to the incidence of breast cancer, regardless of which implied value, the path coefficient is the largest. The weight of mapping relationship was the largest, which ultimately leaded to the highest degree of impact on breast cancer incidence. In addition, social public wealth (GDP) has a greater impact on the incidence of breast cancer. Its negative value $(-0.51)$ reflected that the incidence of breast cancer declines with the increase of GDP, which was benefited from the improvement of public health conditions, the development of medical technology, disease prevention and control propaganda and other interventions. The influence of social pressure (UR), personal economic wealth (GDPPC) and population on the incidence of breast cancer is very close (the path coefficients are about 0.2). In different structured variance models, the positive and negative of path coefficients remain unchanged, but the values of path coefficients were different. These deep-seated socioeconomic relations were not discussed here.

Table 4. A structural equations model based on the regression analysis of the incidence and mortality rates of female breast cancer

\begin{tabular}{|c|c|c|c|c|c|c|c|}
\hline Step & & Coefficients & Standard errors & t Stat & P-value & Lower 95\% & Upper 95\% \\
\hline \multirow{6}{*}{ 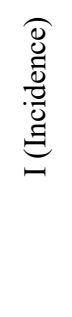 } & Intercept & -20.208 & 2.0584 & -9.8175 & $9.24 \mathrm{E}-20$ & -24.2597 & -16.1563 \\
\hline & Year & 20.7499 & 2.0960 & 9.8999 & $5.02 \mathrm{E}-20$ & 16.6242 & 24.8756 \\
\hline & GDP & -0.5088 & 0.0550 & -9.2508 & $5.74 \mathrm{E}-18$ & -0.6171 & -0.4006 \\
\hline & GDPPC & 0.1795 & 0.0616 & 2.9114 & 0.0039 & 0.0581 & 0.3008 \\
\hline & UR & 0.1864 & 0.0371 & 5.0271 & 8.87E-07 & 0.1134 & 0.2594 \\
\hline & Population & 0.1956 & 0.0282 & 6.9352 & $2.77 \mathrm{E}-11$ & 0.1401 & 0.2511 \\
\hline
\end{tabular}




\begin{tabular}{|c|c|c|c|c|c|c|c|}
\hline \multirow{4}{*}{ 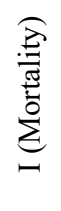 } & Intercept & 3.1114 & 2.7758 & 1.1209 & $\underline{0.2633}$ & -2.3526 & 8.5755 \\
\hline & Year & -2.6725 & 2.8265 & -0.9455 & $\underline{0.3452}$ & -8.2364 & 2.8913 \\
\hline & GDP & -0.3906 & 0.0742 & -5.2658 & $2.77 \mathrm{E}-7$ & -0.5366 & -0.2446 \\
\hline & GDPPC & 0.2654 & 0.0831 & 3.1927 & 0.0016 & 0.1018 & 0.4290 \\
\hline \multirow{5}{*}{ II } & UR & 0.1967 & 0.0500 & 3.9332 & 0.0001 & 0.0983 & 0.2952 \\
\hline & Population & 0.0170 & 0.0380 & 0.4475 & $\underline{0.6548}$ & -0.0578 & 0.0919 \\
\hline & Intercept & 12.0378 & 4.2787 & 2.8134 & 0.0052 & 3.6157 & 20.4598 \\
\hline & Year & -12.1658 & 4.3577 & -2.7918 & 0.0056 & -20.7434 & -3.5881 \\
\hline & GDP & 1.3156 & 0.0856 & 15.3741 & $3.42 \mathrm{E}-39$ & 1.1472 & 1.4841 \\
\hline \multirow{5}{*}{ III } & GDPPC & 0.1652 & 0.1295 & 1.2755 & $\underline{0.2032}$ & -0.0898 & 0.4202 \\
\hline & UR & 0.3932 & 0.0746 & 5.2720 & $2.68 \mathrm{E}-07$ & 0.2464 & 0.5400 \\
\hline & Intercept & -23.3425 & 3.1094 & -7.5072 & $7.84 \mathrm{E}-13$ & -29.4629 & -17.2222 \\
\hline & Year & 24.28957 & 3.1530 & 7.7036 & $2.22 \mathrm{E}-13$ & 18.0833 & 30.4958 \\
\hline & GDP & -0.64 & 0.0565 & -11.3269 & $8.63 \mathrm{E}-25$ & -0.7512 & -0.5288 \\
\hline \multirow{3}{*}{ IV } & GDPPC & -0.77568 & 0.0922 & -8.4125 & $1.99 \mathrm{E}-15$ & -0.9572 & -0.5942 \\
\hline & Intercept & -25.0936 & 1.3344 & -18.8053 & $7.37 \mathrm{E}-52$ & -27.7201 & -22.4671 \\
\hline & Year & 25.5634 & 1.3453 & 19.0016 & $1.41 \mathrm{E}-52$ & 22.9154 & 28.2114 \\
\hline \multirow{3}{*}{ V } & GDP & -0.3654 & 0.0291 & -12.5382 & $5.13 \mathrm{E}-29$ & -0.42272 & -0.3080 \\
\hline & Intercept & -6.3643 & 2.6814 & -2.3735 & 0.0183 & -11.6422 & -1.0864 \\
\hline & Year & 6.5029 & 2.7027 & 2.4061 & 0.0168 & 1.1832 & 11.8227 \\
\hline
\end{tabular}

Note: In this structural equations model, the dependent variables (i.e. incidence rate and mortality rate) have the highest ranking. We assume that the other variables are their independent variables no matter whether implied values or not. That is, the breast cancer incidence and mortality rates are no longer used as variables to explore structural equation models after first-order regression. The underlined values of $\mathrm{P}$ in the table indicate the mathematical relationships that are not of statistical significance.

However, the mortality and socioeconomic factors of breast cancer patients are different from the incidence of breast cancer (Figure. 5(b)). The direct impact of year and population were not significantly, and thus we eliminated the two factors. The increase of public wealth helped to reduce the mortality rate of breast cancer patients, but the increase of personal wealth (GDPPC) and social pressure (UR) induced the increase of mortality rate of breast cancer patients. Therefore, reasonable control of personal economic wealth and release of social pressure are helpful to prolong the survival rate of breast cancer patients. The path coefficients obtained by low-order regression are consistent with the incidence variables. 


\section{Discussion}

\subsection{Country-independent GDP}

In Figure 6, the effect of country-independent GDP values on the incidence and mortality of breast cancer in women based on years were shown. As an important macroeconomic indicator, GDP best measured the economic strength and wealth of a country. The national GDP has an economic impact on the living standards and health of citizens. As seen in Fig. 6(a), the influence of GDP on the incidence of diseases shows a significant separation phenomenon. In Fig. 6(b), the effect of GDP on the mortality of diseases showed a significant separation phenomenon.

At lower national GDP (i.e., the national economic status is in poverty), the incidence and mortality of female breast cancer were both higher. In addition, the incidence and mortality are highly concentrated in the range of 50-200 (per 100,000 persons) and 20-60 (per 100,000 persons). Under higher national GDP, where the national economic status was in rich and defining threshold was 10,000 billion, a good quasi-linear relationship between the incidence and mortality of female breast cancer and GDP was shown. When the GDP was between 10,000 and 30,000 billion, the incidence and mortality of female breast cancer increased slowly with the increase of GDP. This phenomenon might be related to the source of national wealth and industrial level. These factors might produce benefits to working females and work pressure, working environment, and labor intensity. When the GDP was greater than 30,000 billion, the influence of GDP on the incidence and mortality of breast cancer also shows 
a significant bifurcated separation phenomenon, such as "o" and "h/p" in Fig. 6.

There were possible reasons for this pattern. First, some samples reflect that the country were wealthy, where people's living standard significantly improved. In these countries, the increasing incidence and mortality of breast cancer were related to over nutrition, obesity and other problems associated with rapid economic development. In addition, in these countries, the working intensity of the people was surplus/deficiency, which leads to the deviation of individual physique from the healthy range [43]. Secondly, in other emerging economies, with the increase of GDP, the national investment in research and development of preventive medicine and medical technology was enhanced. The national awareness of disease prevention and health has significantly grown, resulting in a gradual decline in the incidence and mortality of breast cancer. Therefore, the low-income countries need allocate sufficient resources to increase screening participation [50]. Thereafter, it is available for the fairly high quality of occurrence data and the adoption of accurate methods to estimate incidence and mortality.

\subsection{GDP per capita}

As an important reference indicator for improving the per capita income level and living standard of residents, the GDP per capita (GDPPC) indirectly reflects the average purchasing power level of social individuals and the degree of independence of life. GDPPC was additionally used as an important economic index for individuals and families, and is related to the objective conditions of life and the judgment of the facts 
and values of the state (e.g. happiness index [44]). High GDPPC might enhance individual happiness through the individual's independent, free, and pleasurable experience in life. The economic index reduces cancer incidence and mortality [45]. In Figure 7, the influence of per capita GDP on the incidence of female breast cancer and the trend of mortality have a power function change trend, but there were large differences in the two key parameters of coefficient and power index. For example, the coefficient of the power function of incidence rate is twice the power function of mortality rate.

There were several reasons for this finding. First, women have a high degree of initiative and enthusiasm in the pursuit of personal value and economic wealth before the onset of breast cancer. At the same time, the increase in personal income, work stress and work intensity were also increased significantly, which results in an increase in the incidence of breast cancer. This result is different from the previous study. However, the effect on mortality is different. Overall mortality was greater among breast cancer patients of the lowest income group than in the highest one [51]. When income is low, expensive medical expenses are major stressor for breast cancer patients. The economic resources have a great impact on families. All aspects of stress will promote the negative beliefs in breast cancer patients, further resulting in accelerated illness and death. This was represented in the upper part of the fitted curve. In wealthy families, the presence of breast cancer patients will not put significant economic pressure on families or related members. After the pain and suffering caused by the disease, breast cancer patients are willing to pay for better therapy and nursing. 
Furthermore, an open-minded attitude of life has reduced the mortality rate to some extent (see the lower part of the fitted curve in Figure 7).

Sociological pressure is accompanied by every process of growth. Specifically, health deterioration from unemployment is likely to be large, and unemployment is a public health problem that needs more focus [52]. Usually, an increase in the unemployment rate is a signal of economic weakness and a reflection of social pressure. For individual, the unemployment or insecure employment closely relates to the degree of happiness and social pressure, specifically psychological complaints and life satisfaction. The impact of unemployment rate on individuals is reflected in psychological stress, which in turn affects an individual's breast cancer incidence and mortality. A $1 \%$ increase in unemployment is associated with a significant increase in colorectal cancer mortality in both men and women [53]. As an important chronic disease, breast cancer was associated with the national unemployment rate (UR) on the affected individuals.

Figure 8 shows the association of the country-independent unemployment rate on the incidence and mortality rates of female breast cancer. The unemployment rate has a reverse corresponding relationship with the economic growth rate, this trend is also consist to the structure equation analysis result. When the unemployment rate is too high, it impacts the income of unemployed group, and also psychologically increases the insecurity of the unemployed. Some unemployed individuals may even cause a series of problems in the case of poor psychological quality [54]. This involuntary diffusion effect will increase the insecurity of workers in the industry, thereby 
increasing the overall insecurity of the society and having an important impact on the physical and mental health of individuals [55].

In Figure 8, with the gradual increase of the unemployment rate, the incidence of breast cancer showed a growth trend of power function $y=42.27 x^{0.48}\left(\mathrm{R}^{2}=0.30\right)$; breast cancer mortality showed a power function $y=12.93 x^{0.48}\left(\mathrm{R}^{2}=0.28\right)$. Incidence and mortality have the same power exponent for the power function of independent variables, which can reflect the consistency of social pressure factors on individuals in the population [56]. This is consistency accounts for the dependence of human beings on social production relations and/or basic survival needs [57]. These needs, which are of great importance to the quality of life and health factors of individuals (e.g., safety, food, and shelter), relate to the cognitive level of individuals themselves.

In addition, there is an approximate three-fold relationship between the coefficient of the incidence power function and the coefficient of the mortality power function, which relates to the individual's desire for life, health and happiness [58]. This result also reads the five-year survival rate (more than 60\%), which is hoped to be a useful information for the patients of breast cancer. In this sense, external social pressure (such as unemployment) might be fitted discretely in the curve of UR-incidence and mortality of breast cancer. However, the effects of unemployment is clearly. Our results are broadly consistent with literature [59], unemployment significantly increases the risk of being dead at the end of follow-up by nearly $50 \%$. The fact may ask for the deep think on the unemployment insurance system for the potential protective effects on the patients of breast cancer [54]. 


\subsection{On mortality-to-incidence ratio}

Five-year survival rate of breast cancer usually is proxied by mortality-toincidence ratio (MIR) of breast cancer for women health [42], Adams et al. investigated the accessibility and importance of mammography services [60]. We further investigated the influences of four socioeconomic factors (including years, GDP, GDPPC and UR) on mortality-to-incidence ratio (MIR) of female breast cancer. In Fig. 9, a sharp increase in the MIR of female patients with breast cancer was revealed with the increase of GDP and GDPPC from 1980 to 2012. MIR obeyed a power function from the trend of the power function of incidence and mortality aforementioned, but the correlation coefficient of regression analysis is small and the dispersion degree of data is high. However, the impact of the increased UR on MIR was almost constant. Therefore, the scatter plot shows that the differentiation was serious, which was mainly related to the individual's physical quality, personal will and survival belief [61].

\section{Conclusions}

Social public wealth has a threshold limit on the regulation of breast cancer occurrence and development. The public wealth produces significant intervention ability until the value reaches at a certain level. The impact of social pressure (unemployment rate) on the incidence and mortality of female breast cancer was not typical monotonous, but showed a power function trend in a specific range. Individual economic wealth has a strong intervention effect on the incidence and mortality of breast cancer. The survival index determined by the ratio of mortality to incidence also 
showed a similar pattern with socioeconomic factors.

Bivariate analysis generally supported the results of univariate analysis. By using path coefficients and structured equations, the multivariable structured equation model analysis further accurately delineate the impact of socioeconomic factors on breast cancer incidence and mortality. The first-order structural equation model was subject to socioeconomic factors, but the second-order structural equation model was related to the correlation between socioeconomic factors. The establishment and expression of mathematical models related to socioeconomic factors were of great value to the accurate analysis and quantitative prediction of the occurrence and development of breast cancer, and further provide an effective theoretical basis for the prevention and treatment of female breast cancer.

\section{Abbreviations}

ANOVA: Analysis of Variance;

MIR: mortality-to-incidence ratio;

GCO: Global Cancer Observatory;

GDP: General Domestic Products;

GDPPC: General Domestic Products per Capita;

SEM: structural equation model;

SS: sum of squares;

UR: unemployment rate. 


\section{Declarations}

\section{Ethics approval and consent to participate}

Not applicable.

\section{Consent for Publication}

Written informed consent for publication was obtained from all participants.

\section{Availability of data and material}

The datasets used or analyzed during the current study are available from the corresponding author on reasonable request.

\section{Competing interests}

The authors have declared that no competing interests exist.

\section{Funding}

This work was supported by Science and technology program of Affiliated Hospital of Jiangsu University (No. jdfyRC2017003) to Q. Peng.

\section{Authors' contributions}

Conceptualization, Qiongle Peng and Xiaoling Ren; Methodology and software, Bing Cui; formal analysis and investigation, Qiongle Peng; visualization and project administration, Henggui Cui; writing and funding acquisition, Qiongle Peng. All 
authors have read and agreed to the published version of the manuscript.

\section{Acknowledgements}

We thanks to Dr. Peng Liu of School of Life Science, Jiangsu University for the useful discussions and suggestions on this paper.

\section{References}

[1] S. Gruskin, E.J. Mills, D. Tarantola, History, principles, and practice of health and human rights, The Lancet, 370 (2007) 449-455.

[2] W. Steffen, K. Richardson, J. Rockström, S.E. Cornell, I. Fetzer, E.M. Bennett, R. Biggs, S.R. Carpenter, W. de Vries, C.A. de Wit, C. Folke, D. Gerten, J. Heinke, G.M. Mace, L.M. Persson, V. Ramanathan, B. Reyers, S. Sörlin, Planetary boundaries: Guiding human development on a changing planet, 347 (2015) 1259855.

[3] M. Jani, B.B. Yimer, T. Sheppard, M. Lunt, W.G. Dixon, Time trends and prescribing patterns of opioid drugs in UK primary care patients with non-cancer pain: A retrospective cohort study, Plos Medicine, 17 (2020).

[4] V.L. Freeman, K.B. Naylor, E.E. Boylan, B.J. Booth, O. Pugach, R.E. Barrett, R.T. Campbell, S.L. McLafferty, Spatial access to primary care providers and colorectal cancer-specific survival in Cook County, Illinois, Cancer Medicine, 9 (2020) 32113223.

[5] L.E. Davis, N.G. Coburn, J. Hallet, C.C. Earle, Y. Liu, S. Myrehaug, A.L. Mahar, Material deprivation and access to cancer care in a universal health care system, Cancer-Am Cancer Soc, 126 (2020) 4545-4552.

[6] L. Highfield, Spatial patterns of breast cancer incidence and uninsured women of mammography screening age, Breast Journal, 19 (2013) 293-301.

[7] R.W. Amin, B.A. Fritsch, J.E. Retzloff, Spatial clusters of breast cancer mortality and incidence in the contiguous USA: 2000-2014, Journal of General Internal Medicine, 34 (2019) 412-419.

[8] I.R. Orimoloye, S.P. Mazinyo, A.M. Kalumba, O.Y. Ekundayo, W. Nel, Implications of climate variability and change on urban and human health: A review, Cities, 91 (2019) 213-223.

[9] C.E. DeSantis, J. Ma, A.G. Sauer, L.A. Newman, A. Jemal, Breast cancer statistics, 2017, racial disparity in mortality by state, CA-A Cancer Journal for Clinicians, 67 (2017) 439-448.

[10] J.M. Braun, G. Kalloo, S.L. Kingsley, N. Li, Using phenome-wide association studies to examine the effect of environmental exposures on human health, 
Environment International, 130 (2019) 104877.

[11] M. Silberberg, V. Martinez-Bianchi, M.J. Lyn, What Is Population Health?, Primary Care: Clinics in Office Practice, (2019).

[12] A.J.B. Smith, A.N. Fader, Association of the affordable care act with ovarian cancer care, Obstetrics and Gynecology, 135 (2020) 257-265.

[13] S. Mueller, C.N. Kline, R.A. Buerki, Y. Chen, Y. Yasui, R. Howell, K.C. Oeffinger, W.M. Leisenring, L.L. Robison, G.T. Armstrong, H.J. Fullerton, K.R. Krull, Stroke impact on mortality and psychologic morbidity within the childhood cancer survivor study, Cancer-Am Cancer Soc, 126 (2020) 1051-1059.

[14] F. Men, C. Gundersen, M.L. Urquia, V. Tarasuk, Association between household food insecurity and mortality in Canada: a population-based retrospective cohort study, Canadian Medical Association Journal, 192 (2020) E53-E60.

[15] H.L. Olsson, M.L. Olsson, The menstrual cycle and risk of breast cancer: a review, Frontiers in Oncology, 10 (2020).

[16] A. Mihor, S. Tomsic, T. Zagar, K. Lokar, V. Zadnik, Socioeconomic inequalities in cancer incidence in Europe: a comprehensive review of population-based epidemiological studies, Radiology and Oncology, 54 (2020) 1-13.

[17] S.-L. Nah, C.-F. Chau, Issues and challenges in defeating world hunger, Trends in Food Science \& Technology, 21 (2010) 544-557.

[18] J.N. Fernandes, I.K. Moise, G.L. Maranto, J.C. Beier, Revamping Mosquito-borne Disease Control to Tackle Future Threats, Trends in Parasitology, 34 (2018) 359368.

[19] I.C. Avila, K. Kaschner, C.F. Dormann, Current global risks to marine mammals: Taking stock of the threats, Biological Conservation, 221 (2018) 44-58.

[20] D. O'Connor, D. Hou, J. Ye, Y. Zhang, Y.S. Ok, Y. Song, F. Coulon, T. Peng, L. Tian, Lead-based paint remains a major public health concern: A critical review of global production, trade, use, exposure, health risk, and implications, Environment International, 121 (2018) 85-101.

[21] G. Cifu, H. Arem, Adherence to lifestyle-related cancer prevention guidelines and breast cancer incidence and mortality, Annals of Epidemiology, 28 (2018) 767-773.

[22] N. Houssami, G. Kirkpatrick-Jones, N. Noguchi, C.I. Lee, Artificial Intelligence (AI) for the early detection of breast cancer: a scoping review to assess AI's potential in breast screening practice, Expert Review of Medical Devices, 16 (2019) 351-362.

[23] W.F. Anderson, P.S. Rosenberg, A. Prat, C.M. Perou, M.E. Sherman, How many etiological subtypes of breast cancer: two, three, four, or more?, Journal of the National Cancer Institute, 106 (2014) dju165.

[24] G. Cheng, J. Zielonka, B.P. Dranka, D. McAllister, A.C. Mackinnon, J. Joseph, B. Kalyanaraman, Mitochondria-targeted drugs synergize with 2-deoxyglucose to trigger breast cancer cell death, Cancer Research, 72 (2012) 2634-2644.

[25] R. Nahta, D. Yu, M.-C. Hung, G.N. Hortobagyi, F.J. Esteva, Mechanisms of Disease: understanding resistance to HER2-targeted therapy in human breast cancer, Nature Clinical Practice Oncology, 3 (2006) 269-280.

[26] F. Taban, N. Elia, E. Rapiti, C. Rageth, G. Fioretta, S. Benhamou, G.T. Lam, E. David-Montefiore, C. Bouchardy, Impact of experience in breast cancer surgery on 
survival: the role of quality of care in a registry-based cohort, Swiss Medical Weekly, 149 (2019).

[27] C.E. DeSantis, J.M. Ma, M.M. Gaudet, L.A. Newman, K.D. Miller, A.G. Sauer, A. Jemal, R.L. Siegel, Breast cancer statistics, 2019, CA-A Cancer Journal for Clinicians, 69 (2019) 438-451.

[28] C. Wu, M. Li, H. Meng, Y. Liu, W. Niu, Y. Zhou, R. Zhao, Y. Duan, Z. Zeng, X. Li, G. Li, W. Xiong, M. Zhou, Analysis of status and countermeasures of cancer incidence and mortality in China, Science China-Life Sciences, 62 (2019) 640-647.

[29] A. Hinzey, M.M. Gaudier-Diaz, M.B. Lustberg, A.C. DeVries, Breast cancer and social environment: getting by with a little help from our friends, Breast Cancer Research, 18 (2016) 54.

[30] D.R. Williams, S.A. Mohammed, A.E. Shields, Understanding and effectively addressing breast cancer in African American women: Unpacking the social context, Cancer-Am Cancer Soc, 122 (2016) 2138-2149.

[31] S.J. Kim, A.E. Glassgow, K.S. Watson, Y. Molina, E.A. Calhoun, Gendered and racialized social expectations, barriers, and delayed breast cancer diagnosis, Cancer-Am Cancer Soc, 124 (2018) 4350-4357.

[32] A. Ikeda, I. Kawachi, H. Iso, M. Iwasaki, M. Inoue, S. Tsugane, Social support and cancer incidence and mortality: the JPHC study cohort II, Cancer Causes \& Control, 24 (2013) 847-860.

[33] A.L. Falisi, K.P. Wiseman, A. Gaysynsky, J.K. Scheideler, D.A. Ramin, W.y.S.J.J.o.C.S. Chou, Social media for breast cancer survivors: a literature review, Journal of Cancer Survivorship, 11 (2017) 808-821.

[34] D. Trusson, A. Pilnick, Between stigma and pink positivity: women's perceptions of social interactions during and after breast cancer treatment, Sociol Health Illn, 39 (2017) 458-473.

[35] S. Thyagarajan, Y. Zhang, S. Thapa, M.S. Allen, N. Phillips, P. Chaudhary, M.V. Kashyap, J.K. Vishwanatha, Comparative analysis of racial differences in breast tumor microbiome, Scientific Reports, 10 (2020).

[36] M. Lagerlund, R. Bellocco, P. Karlsson, G. Tejler, M. Lambe, Socio-economic factors and breast cancer survival - a population-based cohort study (Sweden), Cancer Causes \& Control, 16 (2005) 419-430.

[37] A. Lundqvist, E. Andersson, I. Ahlberg, M. Nilbert, U. Gerdtham, Socioeconomic inequalities in breast cancer incidence and mortality in Europe-a systematic review and meta-analysis, European Journal of Public Health, 26 (2016) 804-813.

[38] A.K. Montoya, A.F. Hayes, Two-condition within-participant statistical mediation analysis: A path-analytic framework, Psychological Methods, 22 (2017) 6-27.

[39] K.J. Preacher, Z. Zhang, M.J. Zyphur, Multilevel structural equation models for assessing moderation within and across levels of analysis, Psychological Methods, 21 (2016) 189-205.

[40] K. Carlsen, M. Ewertz, S.O. Dalton, J.H. Badsberg, M. Osler, Unemployment among breast cancer survivors, Scandinavian Journal of Public Health, 42 (2014) 319-328.

[41] C.L. Odahowski, J.R. Hébert, J.M. Eberth, Regional variation in lung and bronchus 
cancer survival in the US using mortality-to-incidence ratios, Spatial and Spatiotemporal Epidemiology, 26 (2018) 107-112.

[42] R. Sharma, Breast cancer incidence, mortality and mortality-to-incidence ratio (MIR) are associated with human development, 1990-2016: evidence from Global Burden of Disease Study 2016, Breast Cancer, 26 (2019) 428-445.

[43] M.S. Floro, Women's well-being, poverty, and work intensity, Feminist Economics, 1 (1995) 1-25.

[44] M.T. Sanz, A. Caselles, J.C. Micó, D. Soler, A stochastic dynamical social model involving a human happiness index, Journal of Computational and Applied Mathematics, 340 (2018) 231-246.

[45] Z. Yang, R. Zheng, S. Zhang, H. Zeng, C. Xia, H. Li, L. Wang, Y. Wang, W. Chen, Comparison of cancer incidence and mortality in three GDP per capita levels in China, 2013, Chinese Journal of Cancer Research, 29 (2017) 385-394.

[46] S.M. Boker, J.J. McArdle, M. Neale, An algorithm for the hierarchical organization of path diagrams and calculation of components of expected covariance, Structural Equation Modeling: A Multidisciplinary Journal, 9 (2002) 174-194.

[47] J.J. McArdle, R.P. McDonald, Some algebraic properties of the Reticular Action Model for moment structures, 37 (1984) 234-251.

[48] K.J. Grimm, N. Ram, Latent growth and dynamic structural equation models, Annual Review of Clinical Psychology, 14 (2018) 55-89.

[49] A.M. Abubakar, M. Ilkan, Impact of online WOM on destination trust and intention to travel: A medical tourism perspective, Journal of Destination Marketing \& Management, 5 (2016) 192-201.

[50] E. Altobelli, L. Rapacchietta, P.M. Angeletti, L. Barbante, F.V. Profeta, R. Fagnano, Breast cancer screening programmes across the who european region: differences among countries based on national income level, International Journal of Environmental Research and Public Health, 14 (2017).

[51] T. Vehko, M. Arffman, K. Manderbacka, E.P. Supsup, I. Keskimaki, Differences in mortality among women with breast cancer by income - a register-based study in Finland, Scandinavian Journal of Public Health, 44 (2016) 630-637.

[52] F. Norstrom, A.K. Waenerlund, L. Lindholm, R. Nygren, K.G. Sahlen, A. Brydsten, Does unemployment contribute to poorer health-related quality of life among Swedish adults?, Bmc Public Health, 19 (2019).

[53] M. Maruthappu, R.A. Watson, J. Watkins, C. Williams, T. Zeltner, O. Faiz, R. Ali, R. Atun, Unemployment, public-sector healthcare expenditure and colorectal cancer mortality in the European Union: 1990-2009, International Journal of Public Health, 61 (2016) 119-130.

[54] E. Renahy, C. Mitchell, A. Molnar, C. Muntaner, E. Ng, F. Ali, P. O'Campo, Connections between unemployment insurance, poverty and health: a systematic review, European Journal of Public Health, 28 (2018) 269-275.

[55] V. Mousteri, M. Daly, L. Delaney, P. Tynelius, F. Rasmussen, Adolescent mental health and unemployment over the lifespan: Population evidence from Sweden, Social Science \& Medicine, 222 (2019) 305-314.

[56] P.J. Cruitt, T.F. Oltmanns, Unemployment and the relationship between borderline 
personality pathology and health, Journal of Research in Personality, 82 (2019).

[57] R.C. Sumner, R. Bennett, A.M. Creaven, S. Gallagher, Unemployment, employment precarity, and inflammation, Brain Behav Immun, 83 (2020) 303-308.

[58] J. Marrone, M.A. Swarbrick, Long-term unemployment: a social determinant underaddressed within community behavioral health programs, Psychiatric Services, 71 (2020) 745-748.

[59] U.G. Gerdtham, M. Johannesson, A note on the effect of unemployment on mortality, Journal of Health Economics, 22 (2003) 505-518.

[60] S.A. Adams, S.K. Choi, J.M. Eberth, D.B. Friedman, M.P. Yip, R.D. Tucker-Seeley, L.T. Wigfall, J.R. Hebert, Is Availability of Mammography Services at Federally Qualified Health Centers Associated with Breast Cancer Mortality-to-Incidence Ratios? An Ecological Analysis, Journal of Womens Health, 24 (2015) 916-923.

[61] A.R. Davies, L. Homolova, C.N.B. Grey, M.A. Bellis, Health and mass unemployment events-developing a framework for preparedness and response, Journal of Public Health, 41 (2019) 665-673. 


\section{Figure Legends}

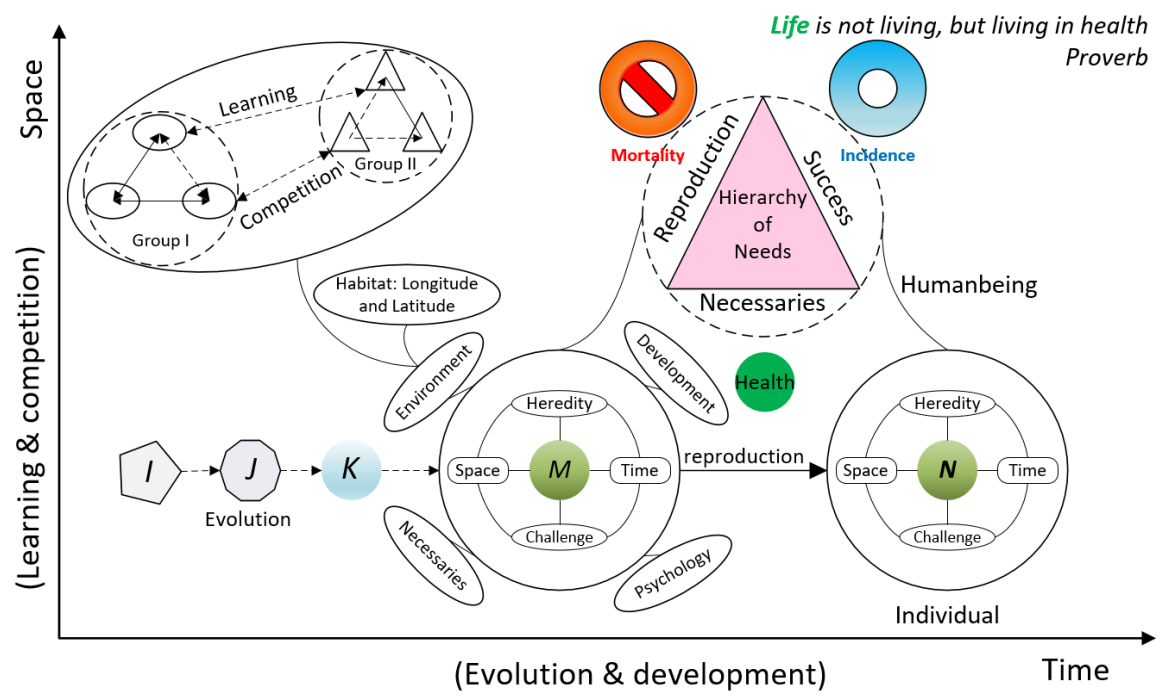

Figure 1 Illustration of the individual health issues from the perspective of human development. 


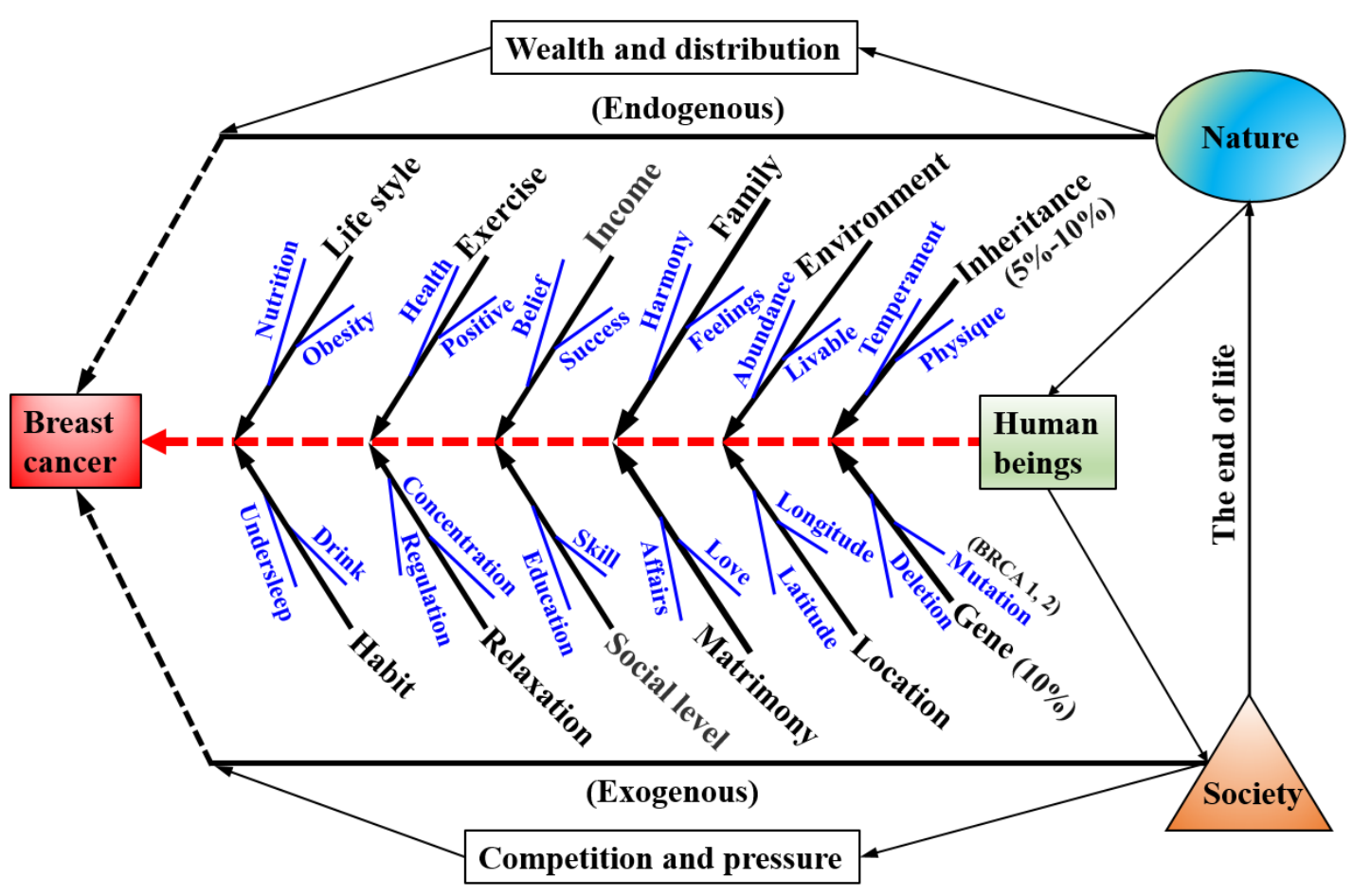

Figure 2 Fishbone diagram of the affecting factors both from nature and society on the breast cancer of women. 

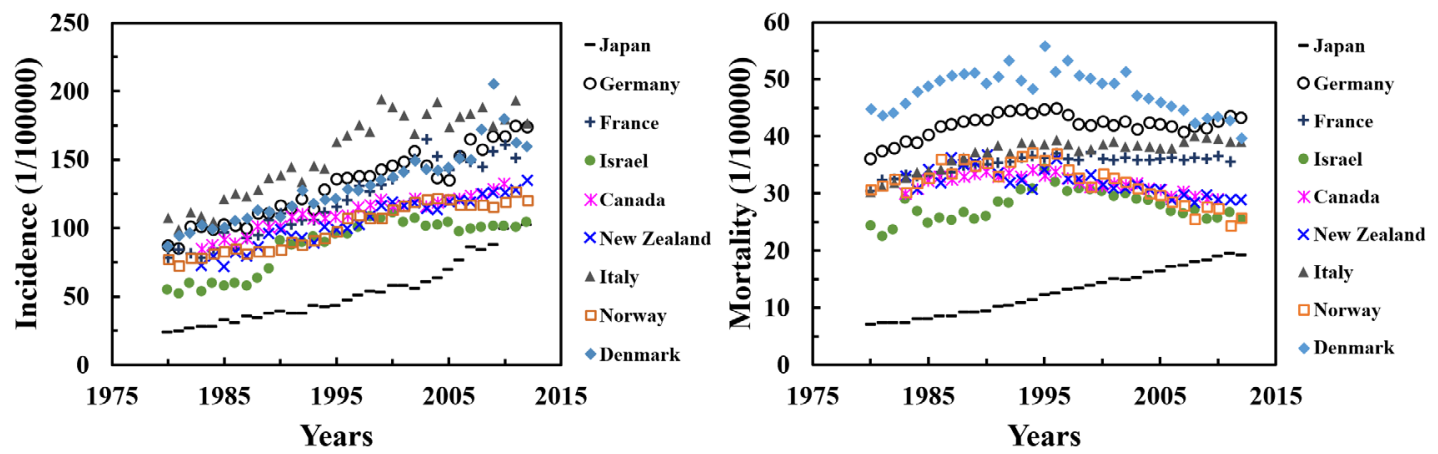

Figure 3 Illustration of incidence and mortality of breast cancer of women in given developed countries after GCO data. 
(a)

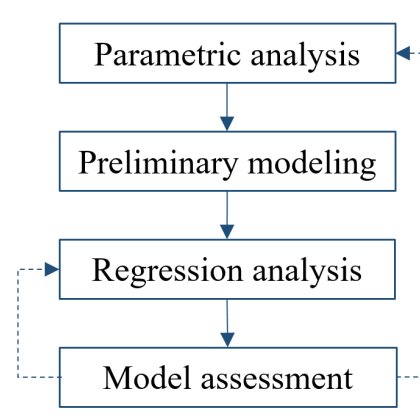

(b)

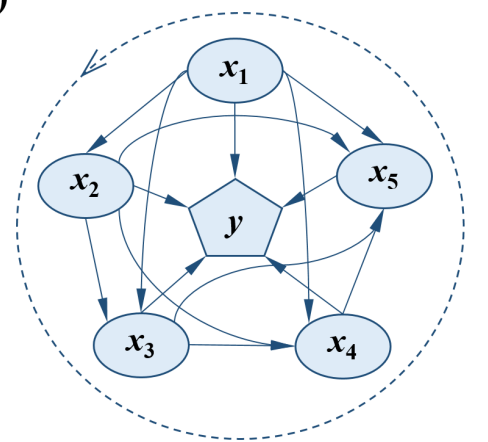

Figure 4 Graphical procedures and structural model for path diagram analysis. 

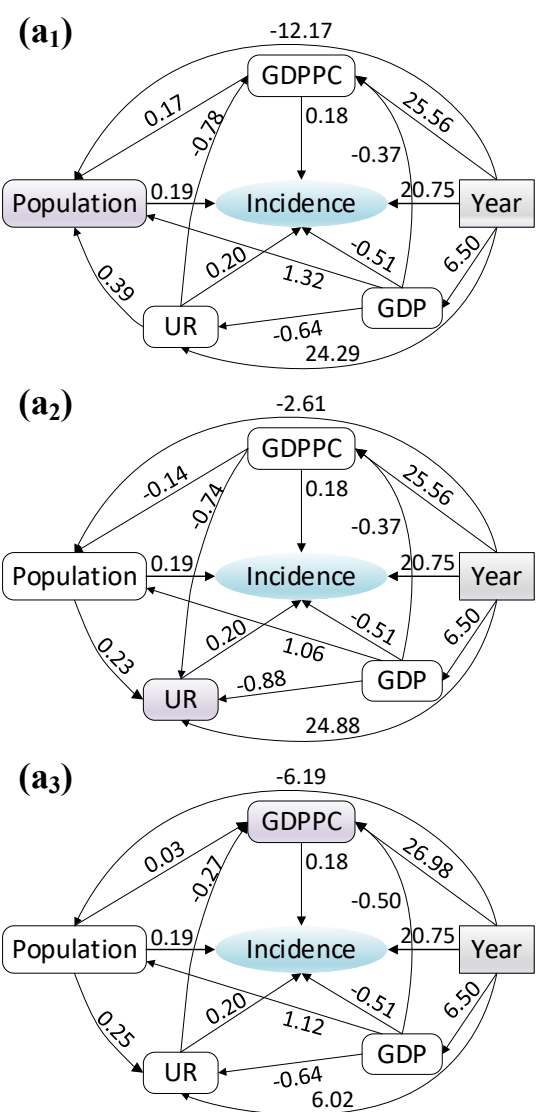
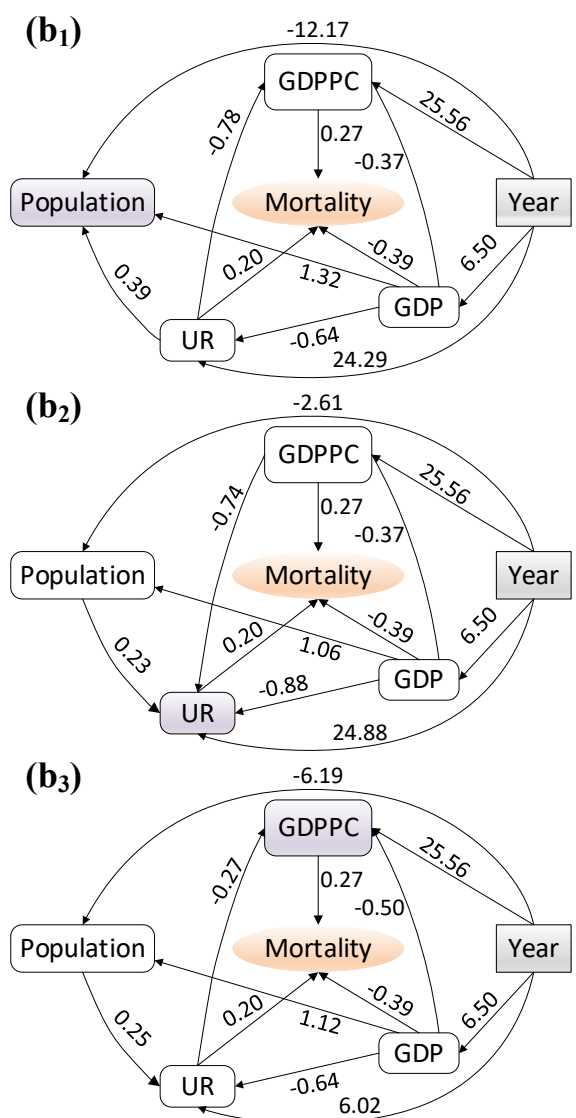

Figure 5 Structural equations model used to illustrate the relation between the incidence and mortality rates and socioeconomic factors: In the corresponding structural equation models, the dependent variables are (a) breast cancer incidence and (b) mortality respectively. Subscripts 1, 2 and 3 represent the structural equation models under three hypothetical conditions. 
(a)

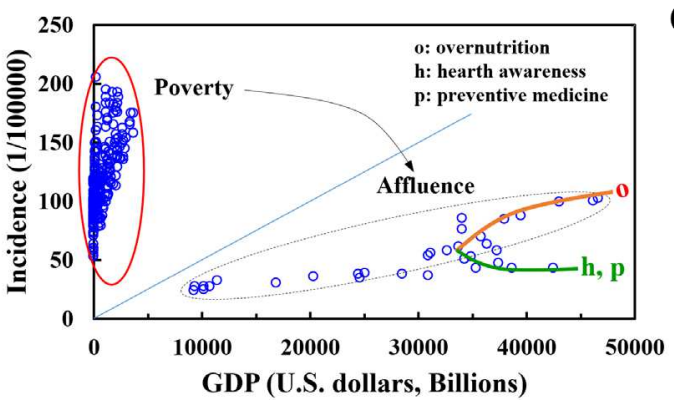

(b)

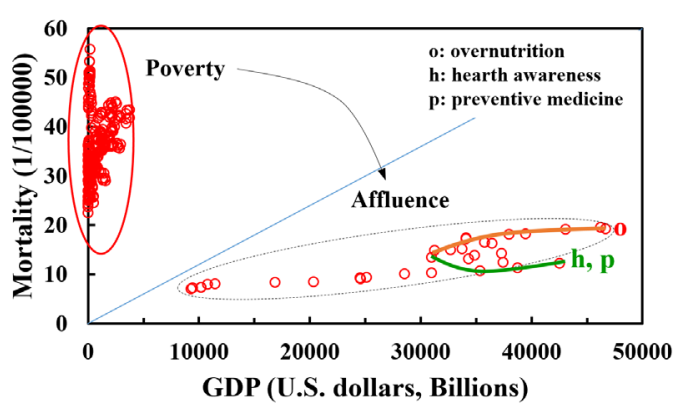

Figure 6 Differentiated effects of social public wealth on incidence and mortality rates of female breast cancer. 
(a)

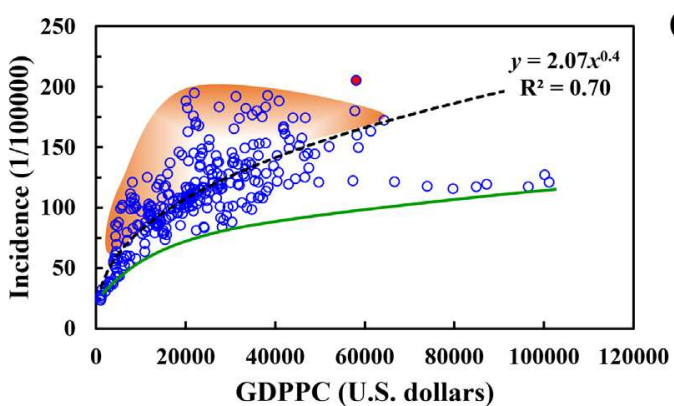

Figure 7 Effects of country-independent GDPPC on the incidence and mortality rates of female breast cancer.

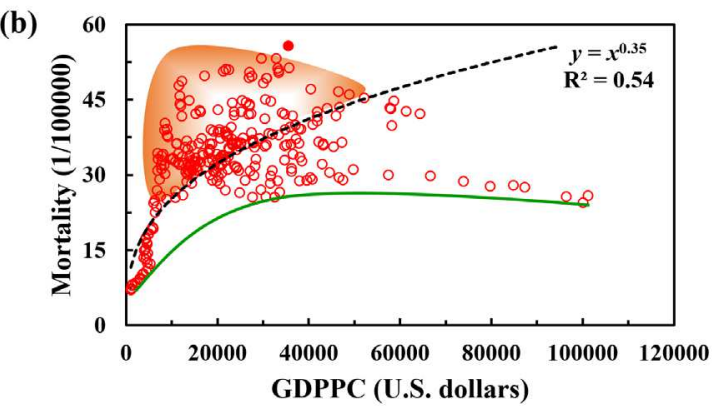



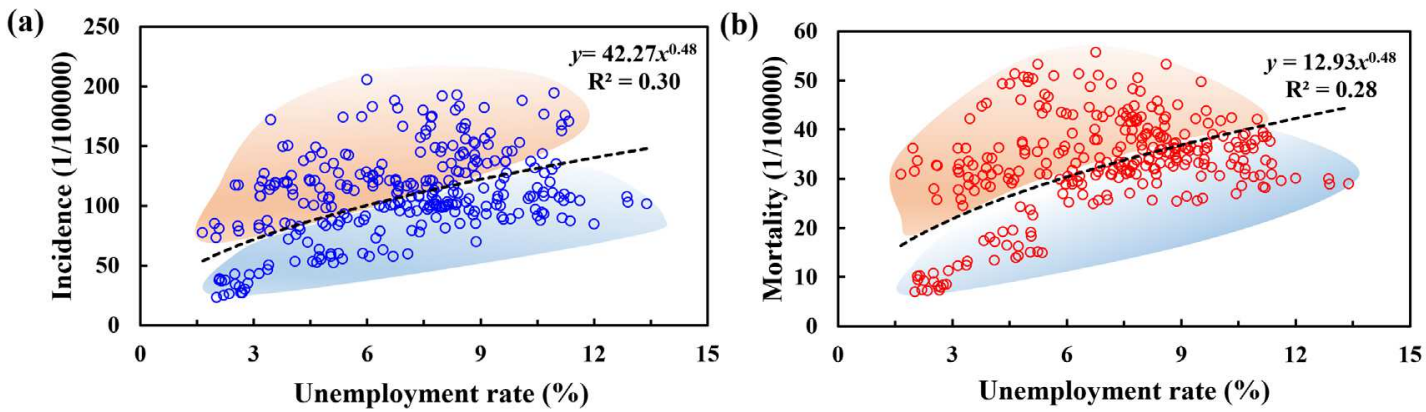

Figure 8 Effects of country-independent sociological UR on the incidence and mortality rates of female breast cancer. 

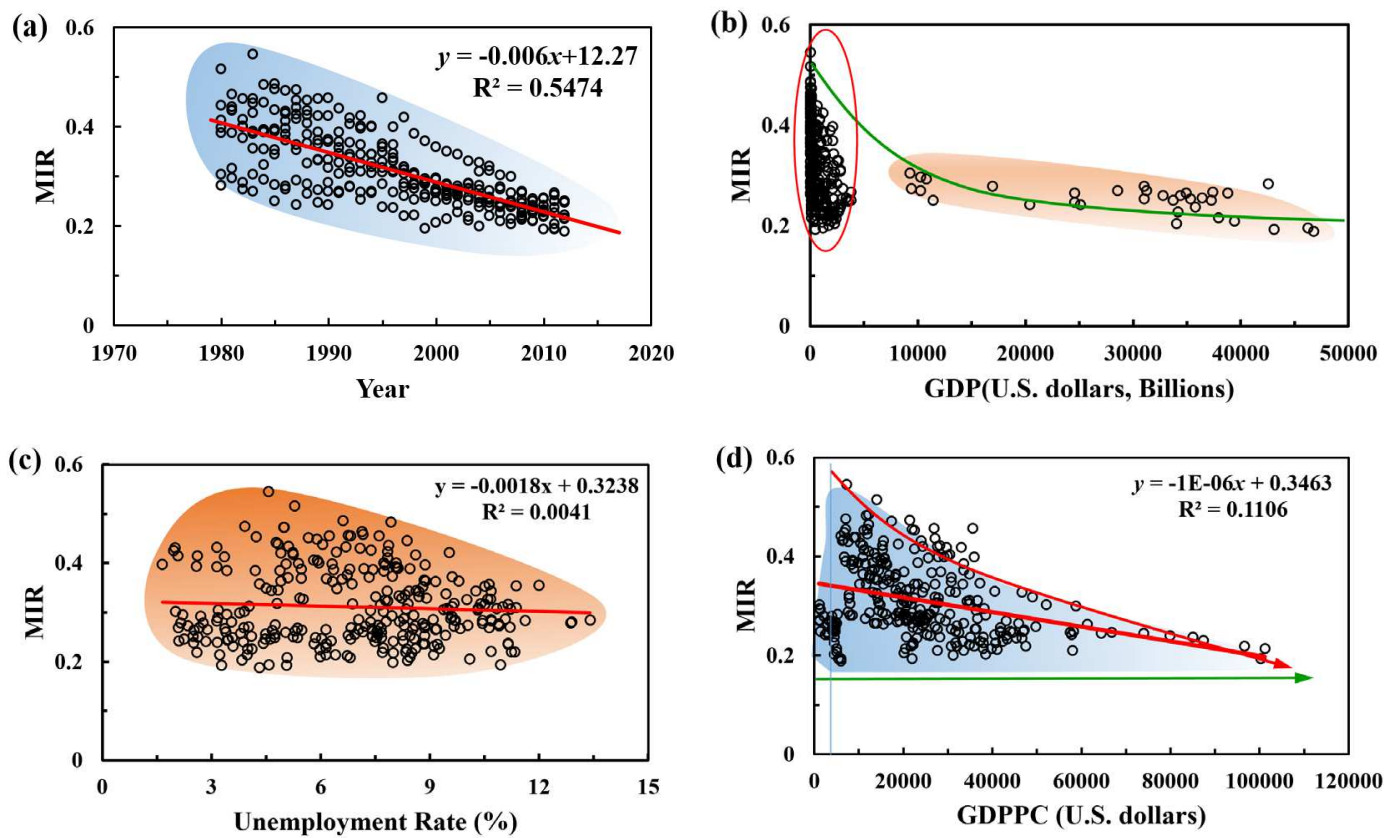

Figure 9 Effects of socioeconomic factors on the mortality-to-incidence ratio (MIR) of female breast cancer. 


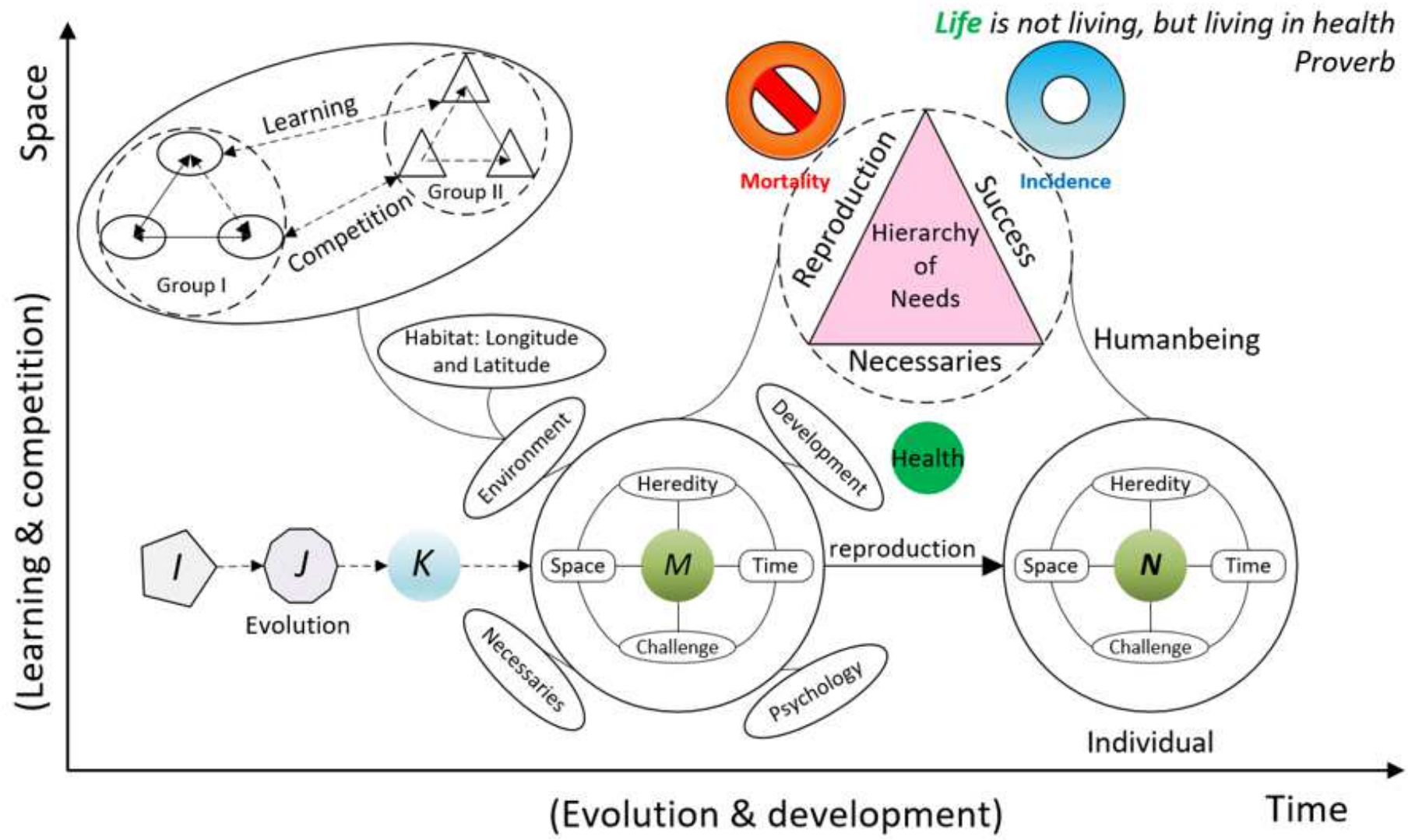

\section{Figure 1}

Illustration of the individual health issues from the perspective of human development. 


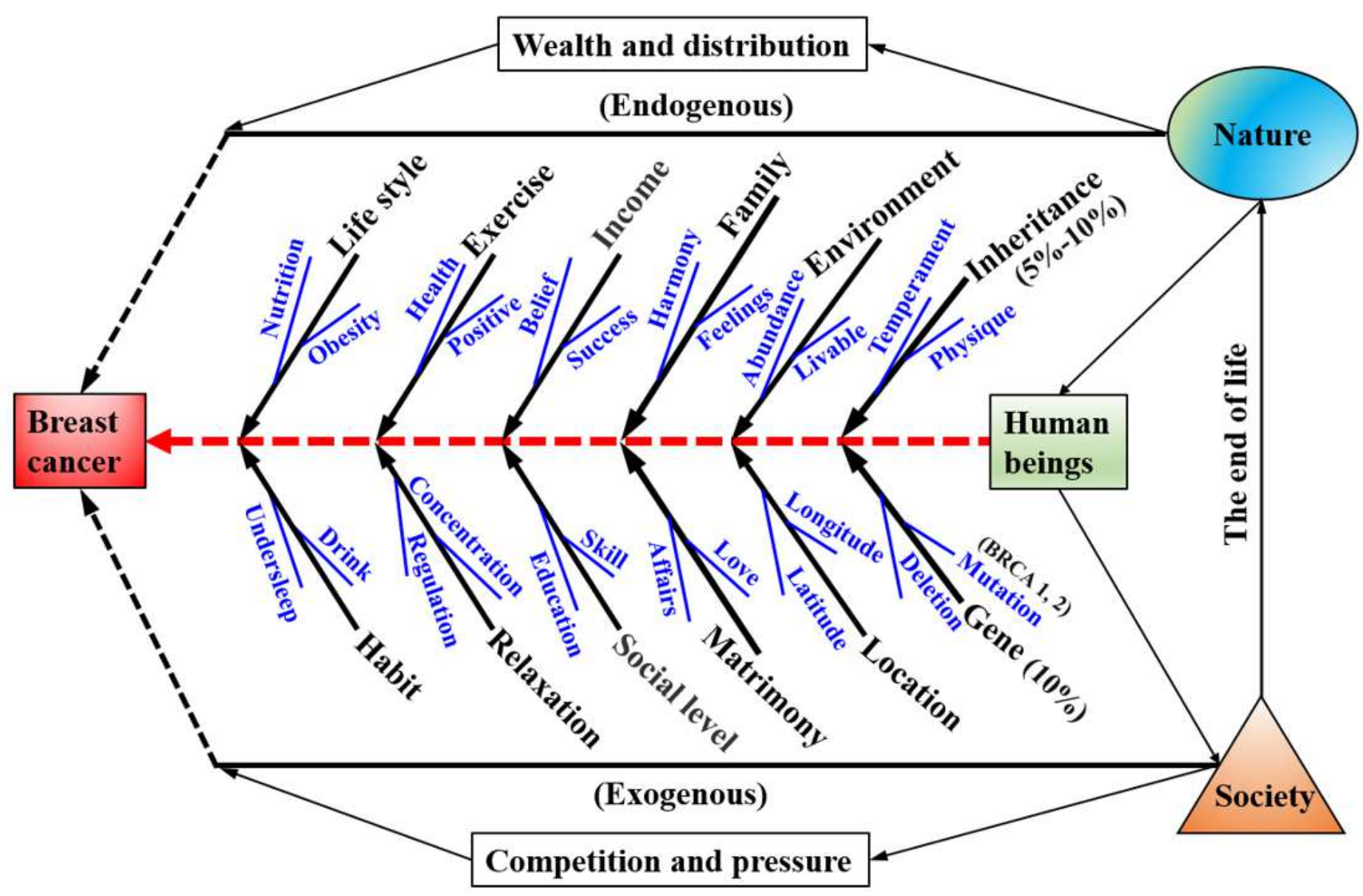

Figure 2

Fishbone diagram of the affecting factors both from nature and society on the breast cancer of women.
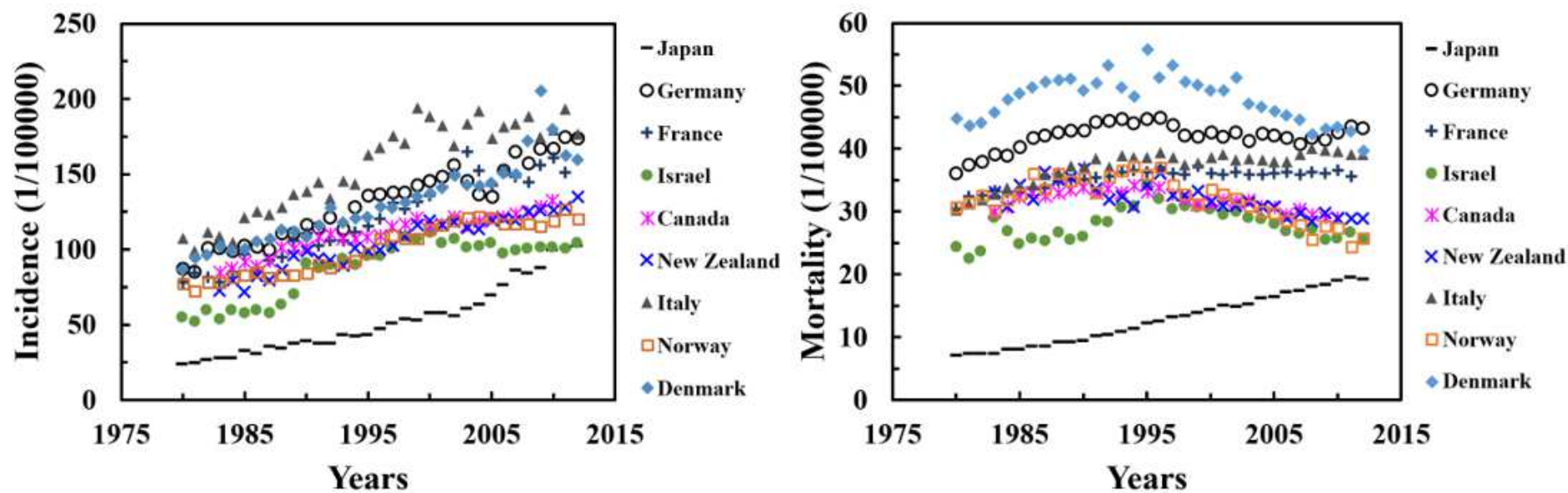

Figure 3

Illustration of incidence and mortality of breast cancer of women in given developed countries after GCO data. 
(a)

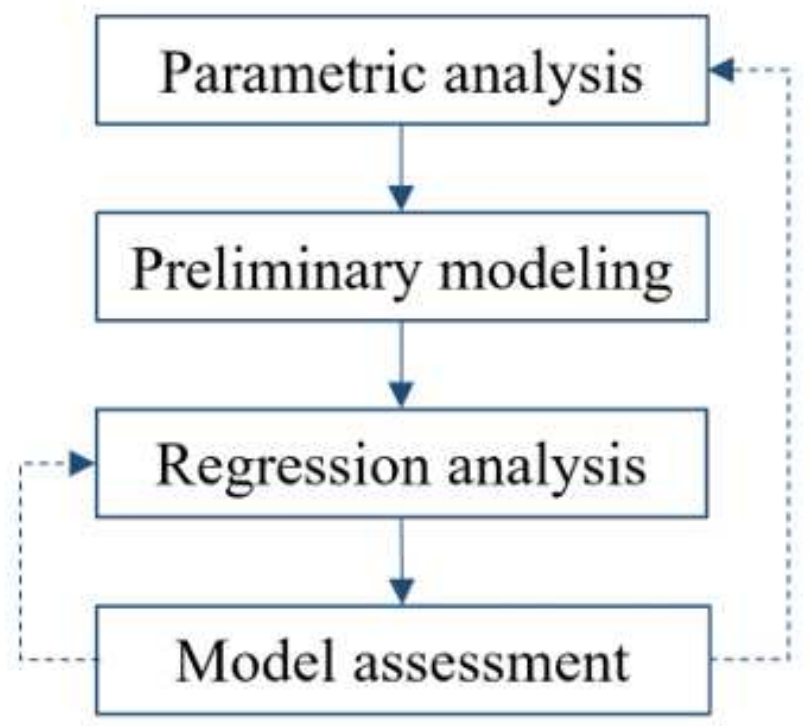

(b)

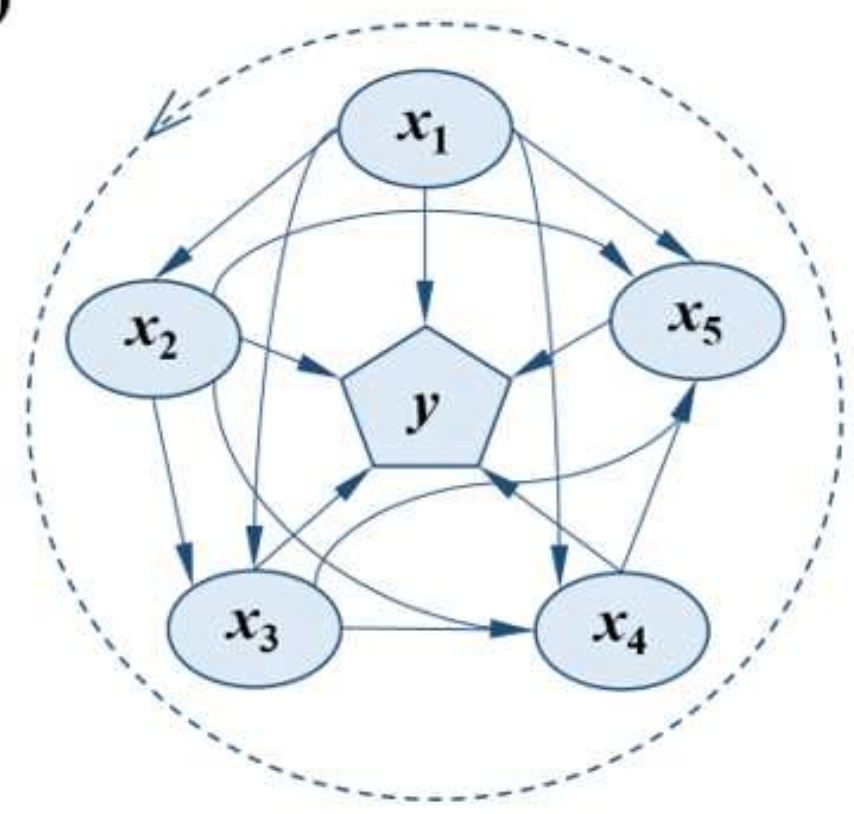

Figure 4

Graphical procedures and structural model for path diagram analysis. 

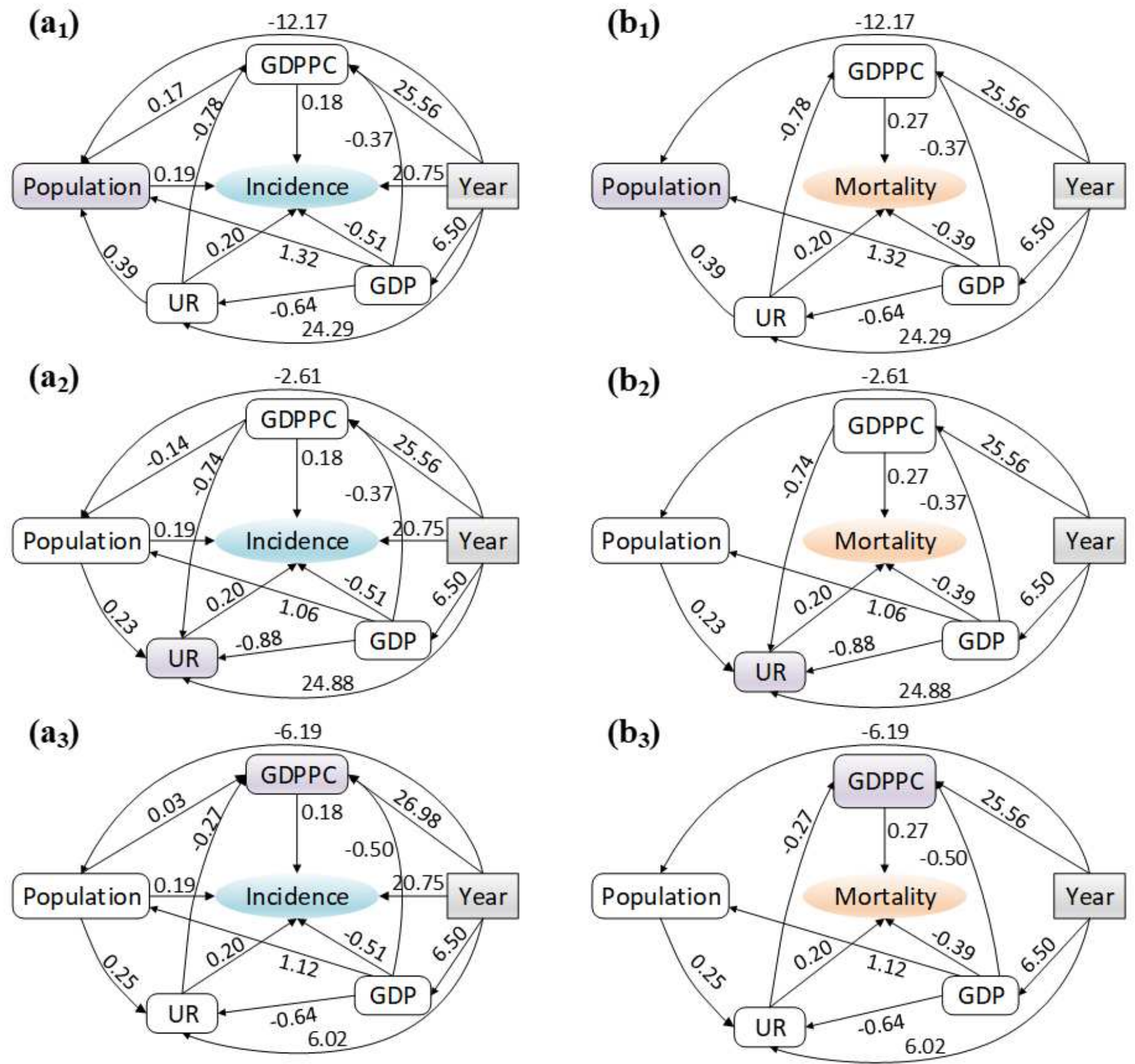

Figure 5

Structural equations model used to illustrate the relation between the incidence and mortality rates and socioeconomic factors: In the corresponding structural equation models, the dependent variables are (a) breast cancer incidence and (b) mortality respectively. Subscripts 1,2 and 3 represent the structural equation models under three hypothetical conditions. 
(a)

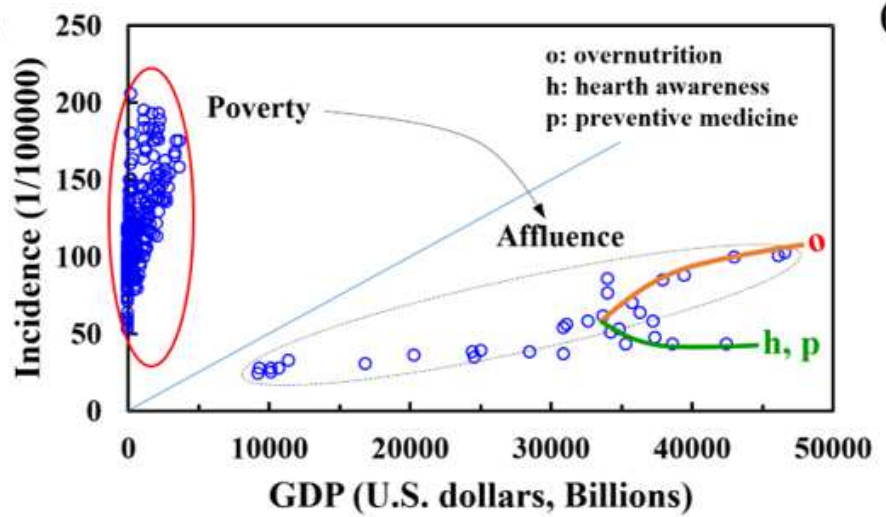

(b)

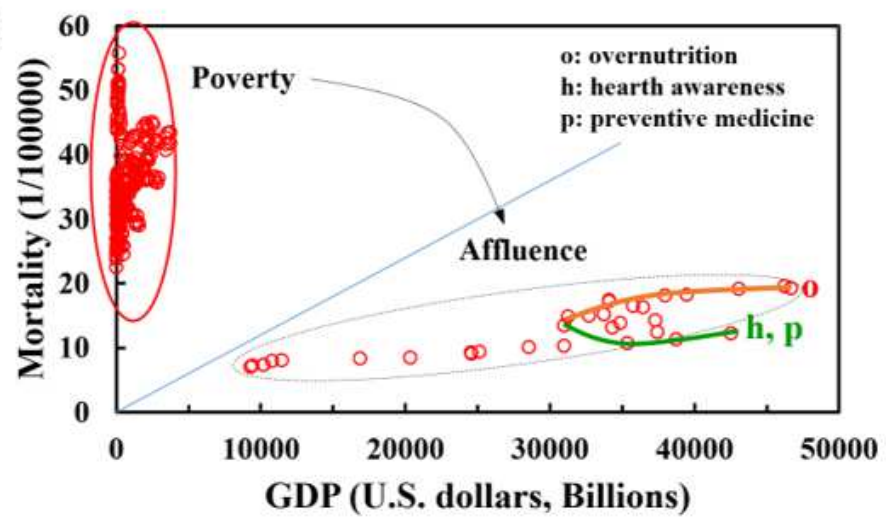

Figure 6

Differentiated effects of social public wealth on incidence and mortality rates of female breast cancer.

(a)

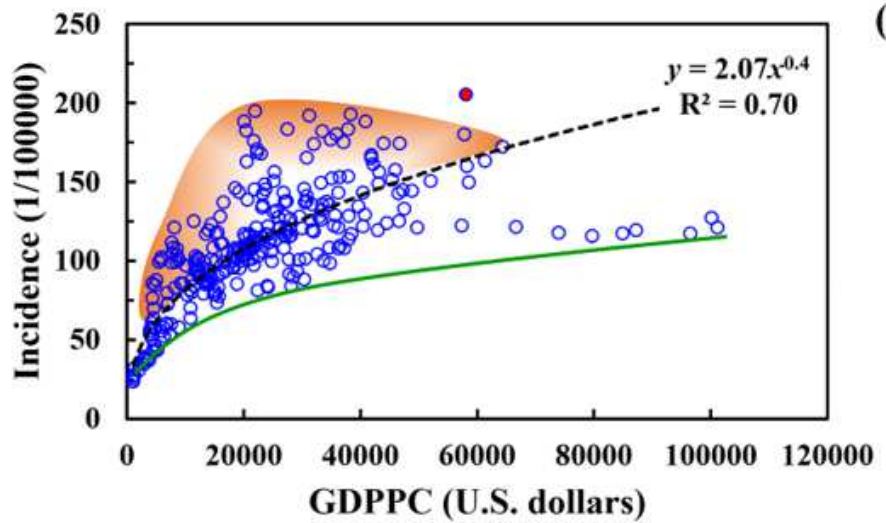

(b)

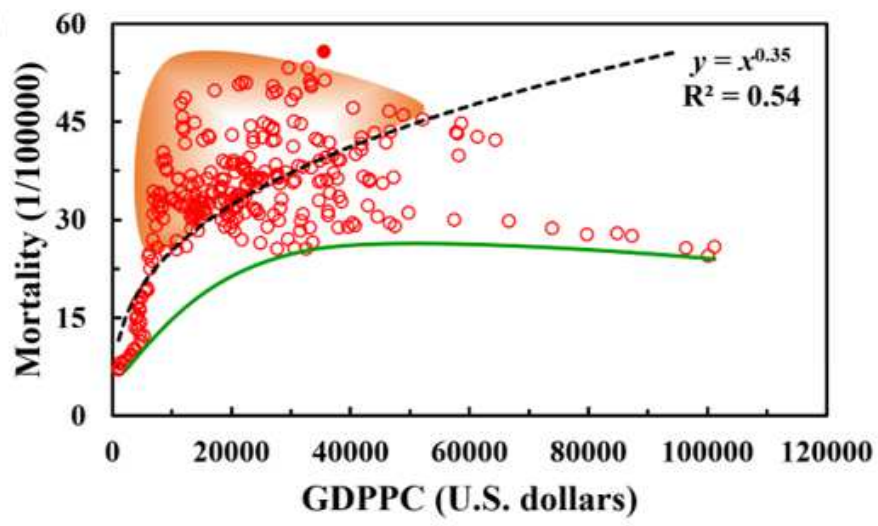

Figure 7

Effects of country-independent GDPPC on the incidence and mortality rates of female breast cancer.

(a)

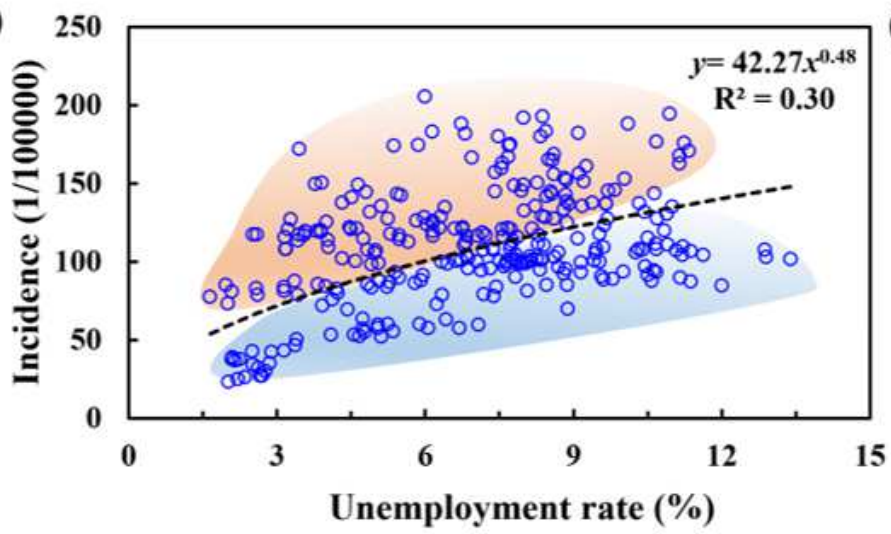

(b)

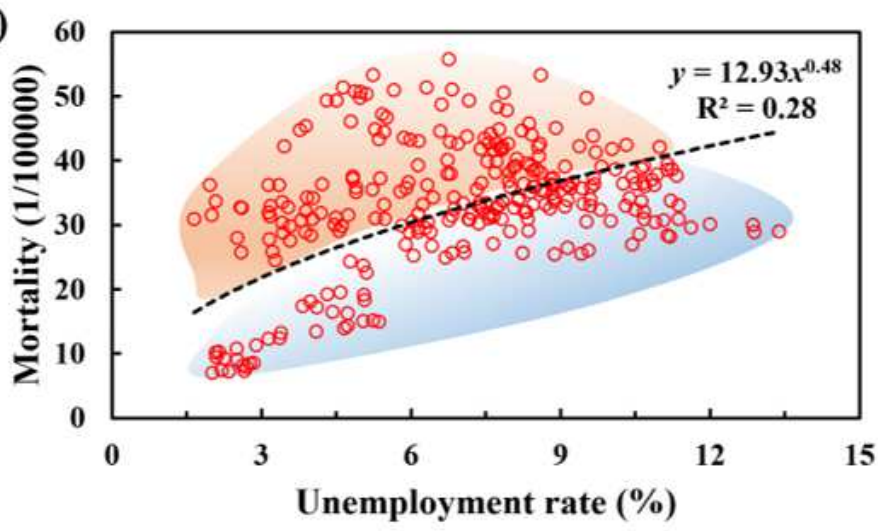

\section{Figure 8}

Effects of country-independent sociological UR on the incidence and mortality rates of female breast cancer. 
(a)

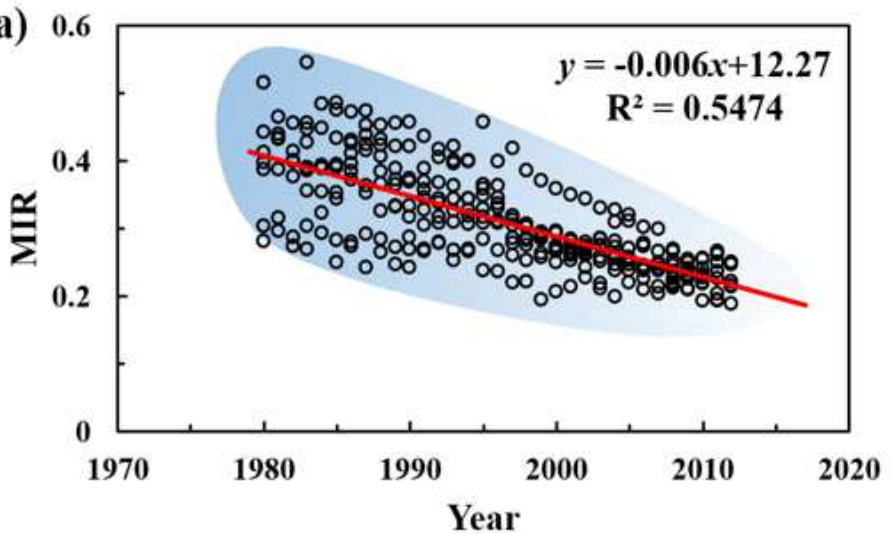

(c)

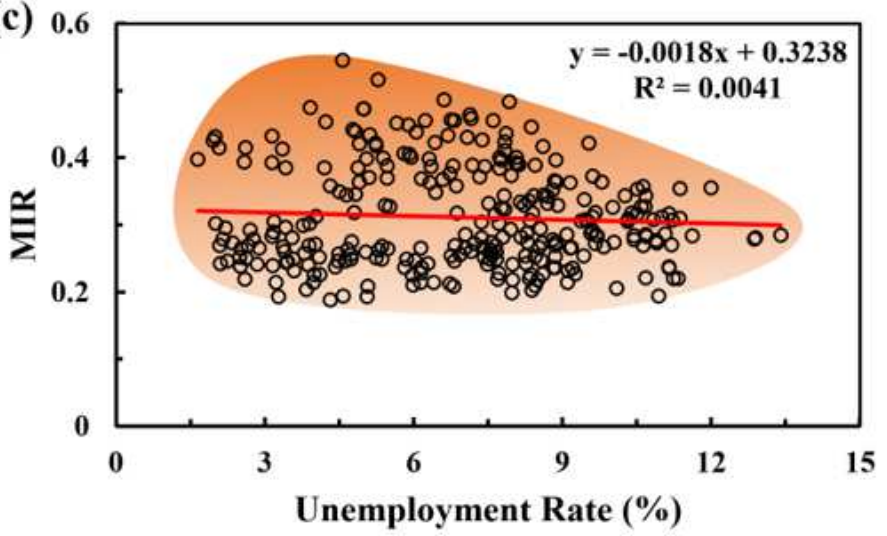

(b) 0.6

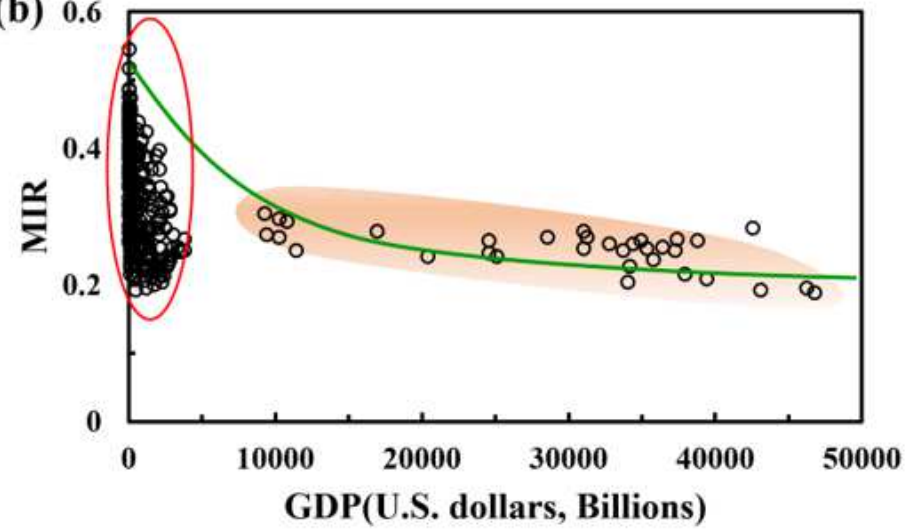

(d)

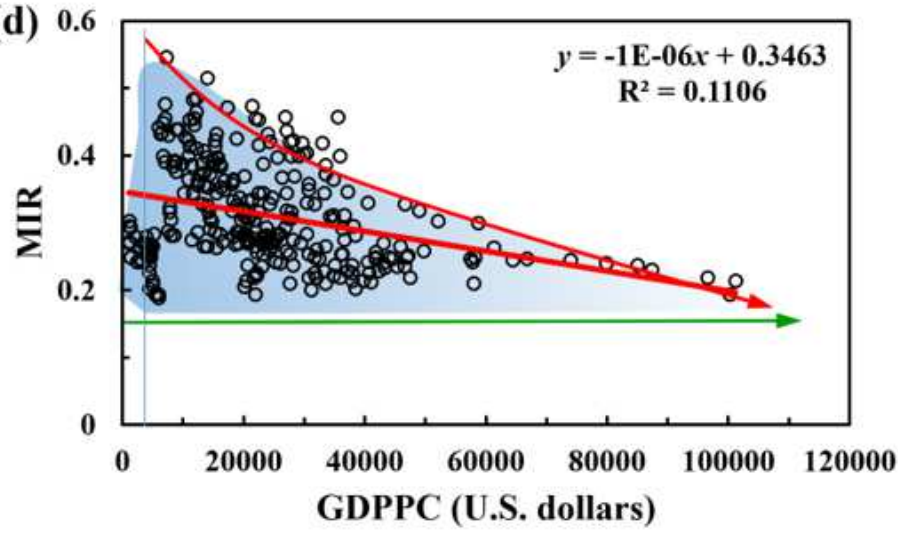

Figure 9

Effects of socioeconomic factors on the mortality-to-incidence ratio (MIR) of female breast cancer.

\section{Supplementary Files}

This is a list of supplementary files associated with this preprint. Click to download.

- Declarations.docx 